\title{
Virtual Interconnection Platform Initiative Scoping Study
}

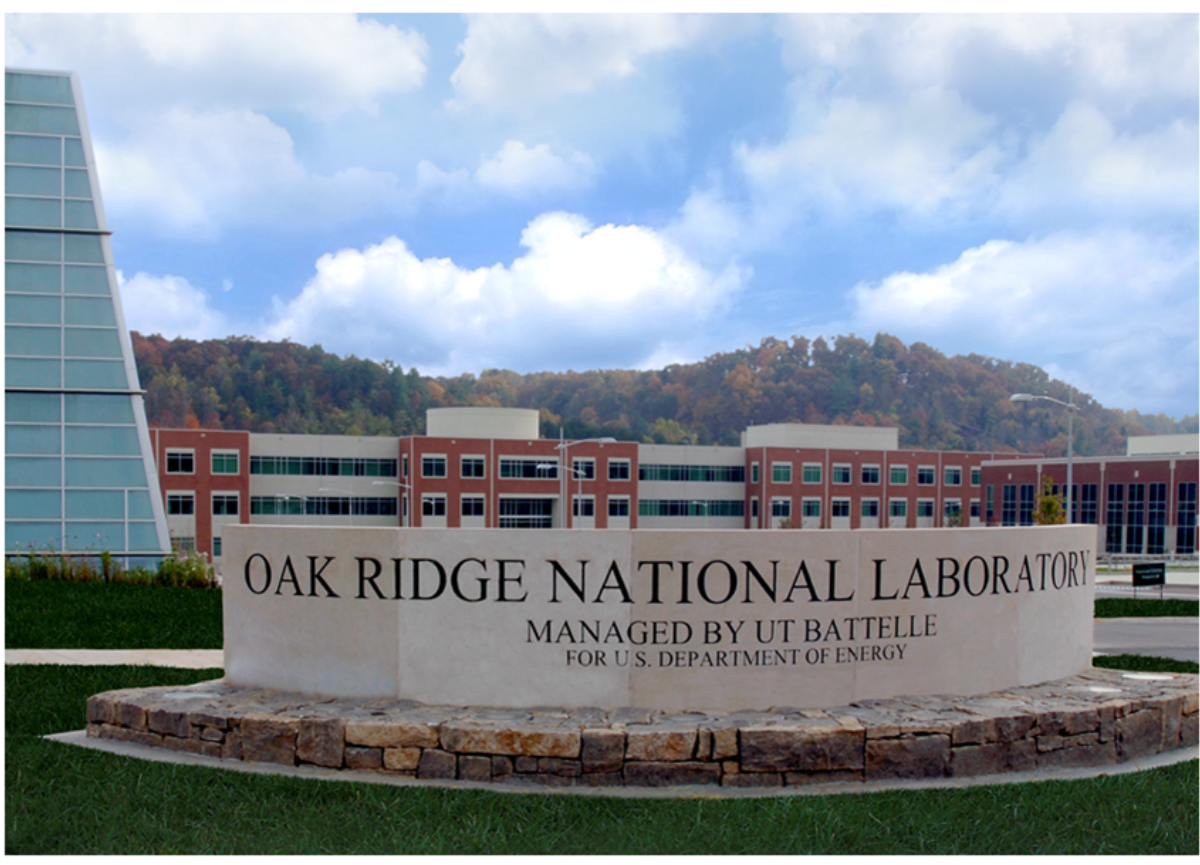

Approved for public release. Distribution is unlimited.
Yong Liu Gefei Kou Zhuohong Pan Jose Gracia Yilu Liu Tom King January 2016 


\section{DOCUMENT AVAILABILITY}

Reports produced after January 1, 1996, are generally available free via the U.S. Department of Energy (DOE) Information Bridge.

Web site http://www.osti.gov/bridge

Reports produced before January 1, 1996, may be purchased by members of the public from the following source.

National Technical Information Service

5285 Port Royal Road

Springfield, VA 22161

Telephone 703-605-6000 (1-800-553-6847)

TDD 703-487-4639

Fax 703-605-6900

E-mail info@ntis.gov

Web site http://www.ntis.gov/support/ordernowabout.htm

Reports are available to DOE employees, DOE contractors, Energy Technology Data Exchange (ETDE) representatives, and International Nuclear Information System (INIS) representatives from the following source.

Office of Scientific and Technical Information

P.O. Box 62

Oak Ridge, TN 37831

Telephone 865-576-8401

Fax 865-576-5728

E-mail reports@osti.gov

Web site http://www.osti.gov/contact.html

This report was prepared as an account of work sponsored by an agency of the United States Government. Neither the United States Government nor any agency thereof, nor any of their employees, makes any warranty, express or implied, or assumes any legal liability or responsibility for the accuracy, completeness, or usefulness of any information, apparatus, product, or process disclosed, or represents that its use would not infringe privately owned rights. Reference herein to any specific commercial product, process, or service by trade name, trademark, manufacturer, or otherwise, does not necessarily constitute or imply its endorsement, recommendation, or favoring by the United States Government or any agency thereof. The views and opinions of authors expressed herein do not necessarily state or reflect those of the United States Government or any agency thereof. 
Electrical and Electronics Systems Research Division

\title{
VIRTUAL INTERCONNECTION PLATFORM INITIATIVE SCOPING STUDY
}

\author{
Yong Liu \\ Gefei Kou \\ Zhuohong Pan \\ Jose Gracia \\ Yilu Liu \\ Tom King
}

Date Published: January 2016

Prepared by OAK RIDGE NATIONAL LABORATORY

Oak Ridge, Tennessee 37831-6283

managed by

UT-BATTELLE, LLC

for the

U.S. DEPARTMENT OF ENERGY

under contract DE-AC05-00OR22725 



\section{CONTENTS}

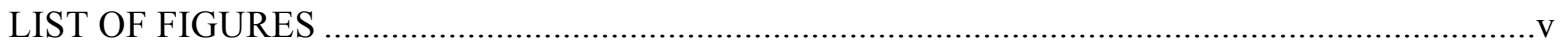

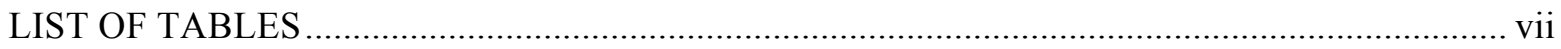

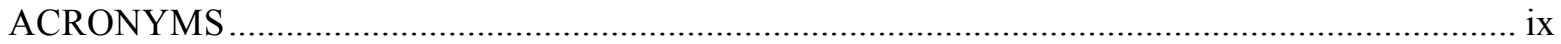

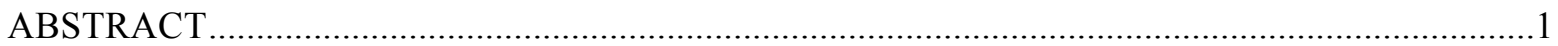

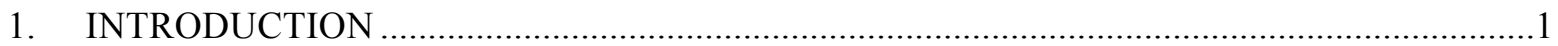

2. FEATURES TO BE EXHIBITED BY THE NOTIONAL GRID .............................................

2.1 VOLTAGE AND FREQUENCY FEATURES ...........................................................

2.2 STEADY-STATE POWER FLOW AND DYNAMIC CHARACTERISTICS ................6

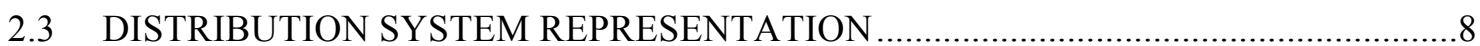

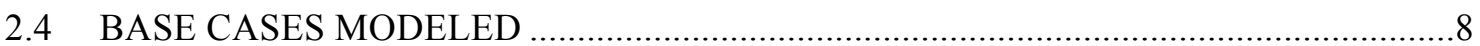

2.5 COMPARISON OF THE NOTIONAL SYSTEM versus the IEEE 118-BUS SYSTEM ..8

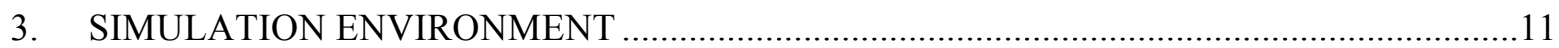

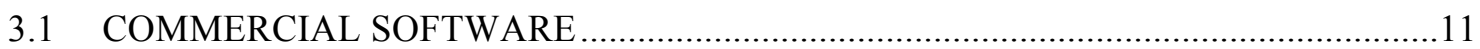

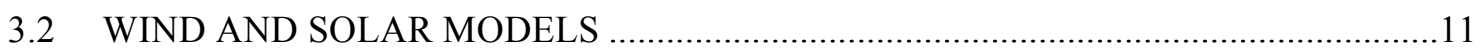

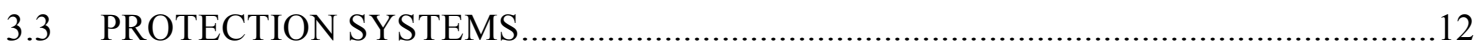

3.4 PLANNING SCENARIOS (PENETRATION OF RENEWABLES, STORAGE,

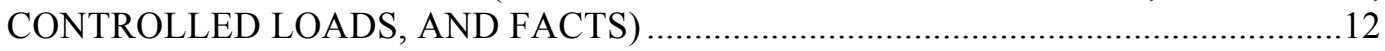

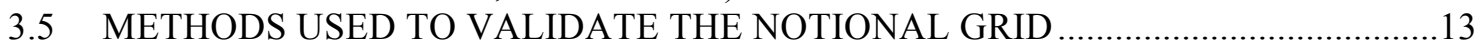

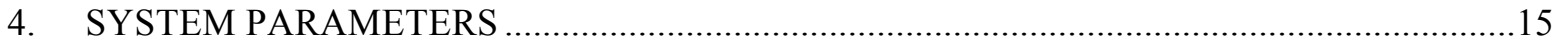

4.1 DEFINE SYSTEM SIZE: TOPOLOGY \& REGIONS, VOLTAGE LEVEL, MW AND

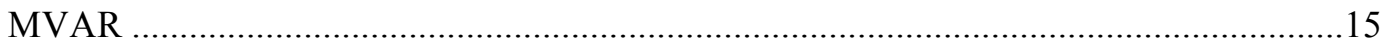

4.2 WIND, SOLAR, OFF-SHORE WIND SIZE AND ALLOCATION ….........................18

4.3 LOCATION OF MAJOR GENERATION AND LOAD CENTERS …............................18

4.4 FACTS, STORAGE, AND HVDC SIZE AND ALLOCATION …................................

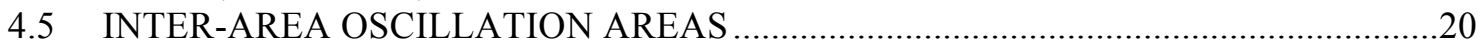

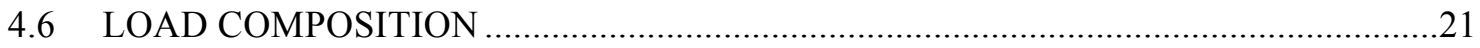

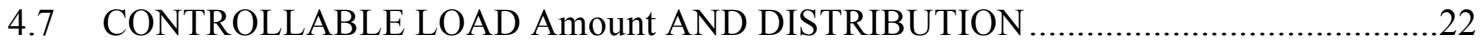

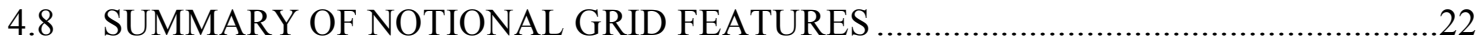

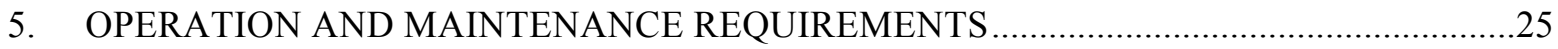

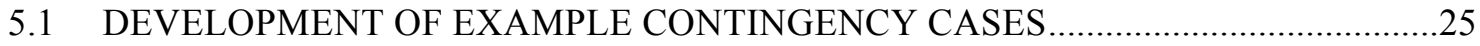

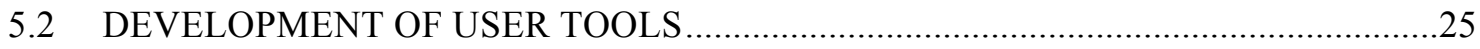

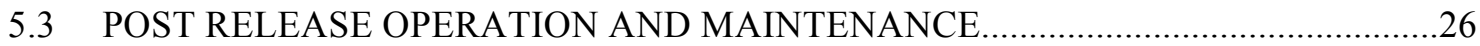

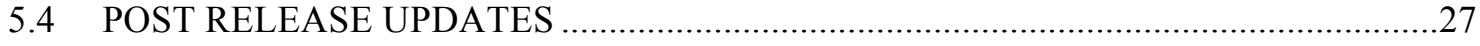

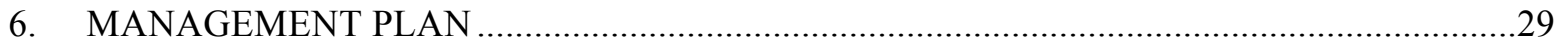

6.1 ESTIMATE RELEASE TIMELINE OF PHASES OF THE PROJECTS …..................29

6.2 DEFINE DOCUMENTATION REQUIRED FOR EACH VERSION .............................

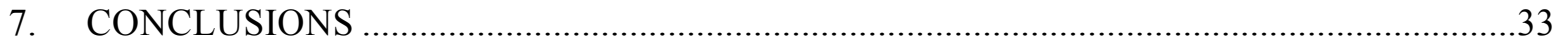

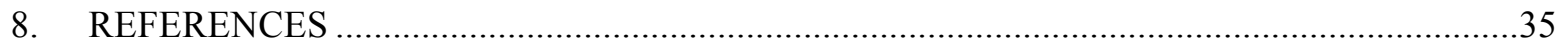

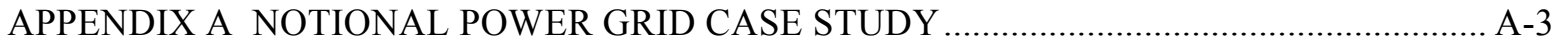

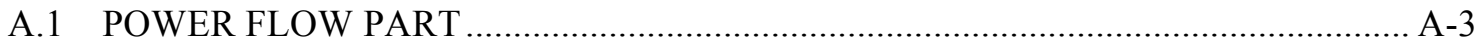

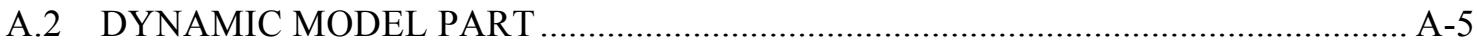

APPENDIX B FEASIBILITY STUDY FOR A REAL TIME NOTIONAL GRID ........................

B.1 BENEFITS OF REAL TIME CONTINOUS OPERATIONS VS OFF-LINE

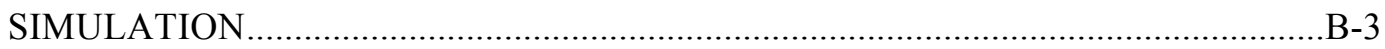

B.2 CHALLENGES FOR REAL TIME CONTINOUS OPERATION ..................................

APPENDIX C. POWER SYSTEM GEOGRAPHIC TOOLBOX (PSGT) …..................................

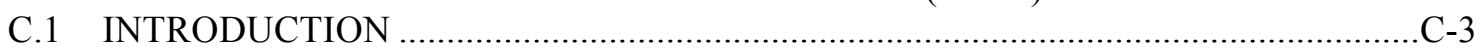

C.2 TOOLBOX ARCHITECTURE ……….......................................................... 


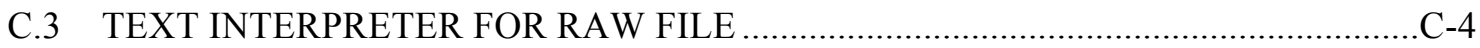

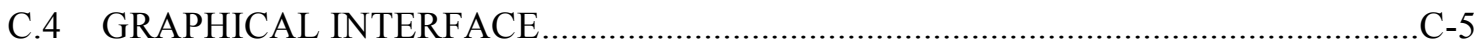

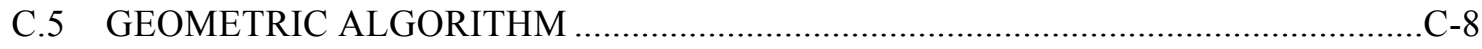




\section{LIST OF FIGURES}

Fig. 1.1. Block diagram of the notional power grid platform ................................................ 2

Fig. 2.1. Geographical footprints of the three major interconnections in the U.S..................... 3

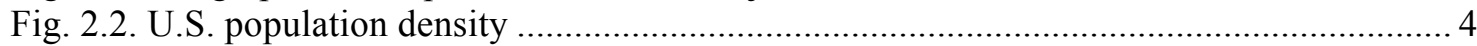

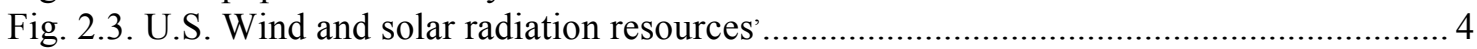

Fig. 2.4. Monthly wind electric power generation in the US (2008-2014)................................. 5

Fig. 2.5. Typical frequency response in the U.S. power grids............................................ 6

Fig. 2.6. Main inter-area oscillation regions in the U.S. EI system. ......................................... 7

Fig. 4.1. Imaginary location of Atlantis continent in the world.............................................. 15

Fig. 4.2. Geographic map of the imaginary Atlantis continent.................................................. 16

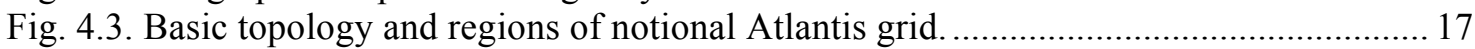

Fig. 4.4. Location of renewable generation on the Atlantis grid. ........................................... 18

Fig. 4.5. Major generation and load centers in the notional Atlantis grid................................ 19

Fig. 4.6. FACTS, energy storage and HVDC line locations in the notional grid. ..................... 20

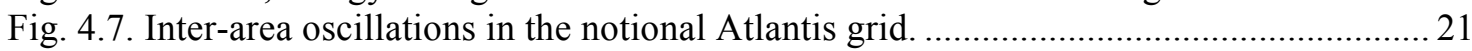

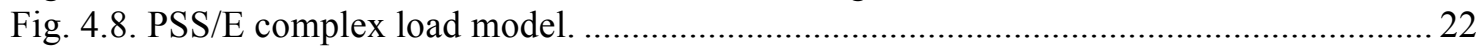

Fig. 4.9. Features of notional Atlantis power grid model in layers. ....................................... 23

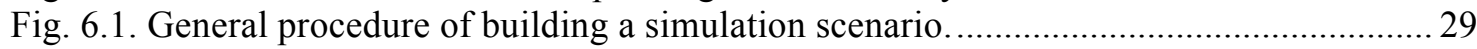

Fig. A.1. Python scripts to cut certain zone out of the original model (part). ......................... A-3

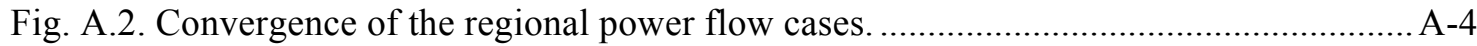

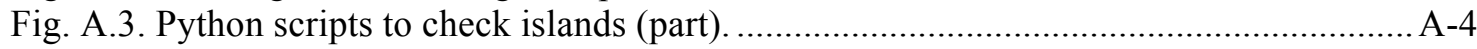

Fig. A.4. Python scripts to real the regional power flows into one file (part). ....................... A-4

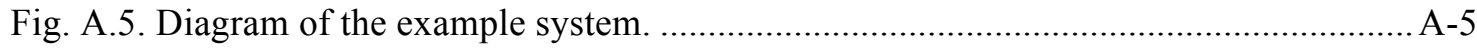

Fig. A.6. Flat run of the example power system............................................................... A-6

Fig. A.7. A generation trip disturbance of the example system............................................ A-6

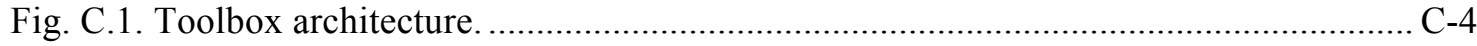

Fig. C.2. Bus information imported from PSS/E raw file.....................................................

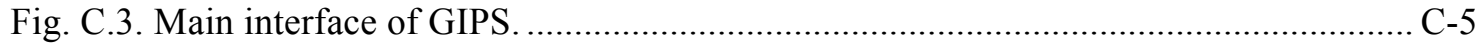

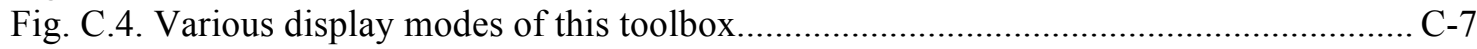

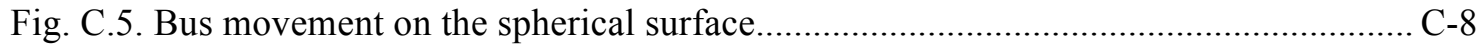

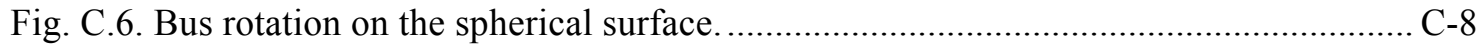





\section{LIST OF TABLES}

Table 2.1. Select IEEE-recommended distribution models in literature ................................ 8

Table 2.2. Comparison of IEEE 118-bus system and notional Atlantis system. ...................... 9

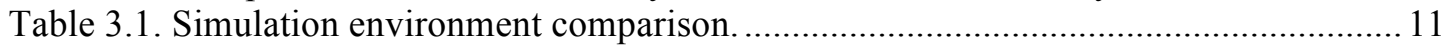

Table 3.2. Scenario information of the notional grid model.................................................... 13

Table 4.1. Generating capacity, number of busses, and voltage levels for each

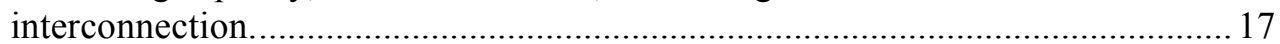

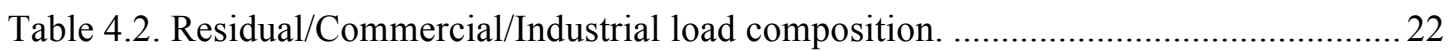

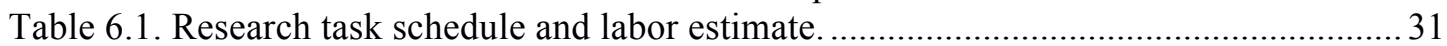

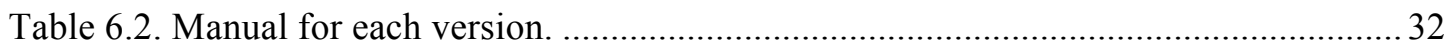

Table B.1. Benefit comparison between continuous and off-line operation......................... B-3

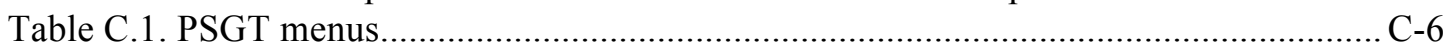





\section{ACRONYMS}

\begin{tabular}{|c|c|}
\hline CAD & Computer-Aided Design \\
\hline EI & Eastern Interconnection (U.S.) \\
\hline ERCOT & Electric Reliability Council of Texas \\
\hline FNET/GridEy & Frequency Monitoring Network/GridEye \\
\hline FACTS & Flexible AC Transmission \\
\hline GIS & Geographic Information System \\
\hline GIPS & Graphical Interface for the Power System \\
\hline HVDC & High Voltage Direct Current \\
\hline MMWG & Multi-Regional Modeling Working Group \\
\hline MFC & Microsoft Visual Studio \\
\hline NPCC & Northeast Power Coordinating Council (U.S.) \\
\hline NI & North Interconnection \\
\hline NWCR & Northwest Coastal Region \\
\hline NCR & North Coastal Region \\
\hline NECR & Northeast Coastal Region \\
\hline NIR & North Inland Region \\
\hline PMU & Phasor Measureemnt Unit \\
\hline PSGT & Power System Geographic Toolbox \\
\hline SI & South Interconnection \\
\hline SWCR & Southwest Coastal Region \\
\hline SECR & Southeast Coastal Region \\
\hline SIR & South Inland Region \\
\hline
\end{tabular}


TIRD

WECC
Text Interface for Raw Data

Western Electricity Coordinating Council (U.S.) 


\begin{abstract}
Due to security and liability concerns, the research community has limited access to realistic largescale power grid platforms to test and validate new operation and control methodologies. It is also difficult for industry to evaluate the relative value of competing new tools without a common platform for comparison. This report proposes to develop a notional large-scale power grid platform that retains the basic features and represents future trends of major U.S. electric interconnections. This platform will include realistic steady-state power flow and dynamic information as well as a pragmatic geospatial distribution of assets. It will be made widely available to the research community for various power system stability and control studies and can be used by industry as a common platform for comparing the efficacies of various new technologies.
\end{abstract}

\title{
1. INTRODUCTION
}

Increasing the contribution from renewable energy sources into the generation mix will result in unprecedented complexity of power system operation and control [1]-[3]. With the advent of phasor measurement units (PMU), real-time control over wide areas seems to finally be on the horizon [4][5]. However, due to security and liability concerns, the research community has limited access to realistical large grid models to test and validate new operation and control methodologies. Industry users have difficulties evaluating the tools developed by vendors and research community without a common platform for comparison. This document provides a scoping study geared toward the development of a large notional (but realistic) electric grid static and dynamic model for public access.

The existing small-sized or highly-reduced power grid models cannot fully replicate the complicated dynamics of modern interconnected power grids. For instance, the Kundur 2-area 4-generator model has been extensively utilized in almost every small-signal stability study [6]-[8]; however, this classic model is so simply structured that only one inter-area oscillation mode exists. Although it is adequate for a concept demonstration of a new damping controller design, it cannot be used in a number of related tasks such as input signal selection and controller coordination. The IEEE 118-bus system, slightly larger in size, is another widely used model for small-signal stability studies [9][10]. With the existence of two dominant inter-area modes, this IEEE model makes it possible to conduct a controller coordination study; however, it is still too simple to test the controls intended to be implemented on large interconnections such as those in the U.S. Furthermore, as pointed out by the Department of Homeland Security in their 2008 workshop report, a national-scale power grid model is needed to address various national concerns such as multi-site terrorist attacks [11]. Additionally, Department of Energy and National Science Foundation have both funded a large number of research projects; the results of those could be better evaluated if a large representative test system existed and were readily accessible. For example, a large benchmark system could help quantify the difference in performance of competing technological solutions offered by various groups of developers.

Large-scale power grid models are used by industry, such as the U.S. Eastern Interconnection (EI) multi-regional modeling working group (MMWG) model at 60,000 busses [12] and the European network of transmission model at 9,000 busses [13]. But access to these models is very limited, and whatever data exists is strictly protected by nondisclosure agreements. Therefore, an openly available, national-scale power grid platform, including both steady-state power flow and dynamics, will benefit the research community at large and accelerate the pace of innovation of power grid technologies.

The proposed notional power grid platform (as shown in Fig. 1.1) will exhibit the basic features (e.g., size, structure, and oscillation modes) of the three U.S. interconnections, and will also represent the 
future trends (e.g., increased use of renewable energy for electricity generation and increased penetration of power electronics-based devices). Based on the project team's experience in developing interconnection-wide steady-state and dynamic models ${ }^{1}$ as well as from observing the dynamic behavior of the North American interconnections through phasor measurements [14]-[19], it is clear that the successful development of a basic large notional grid platform is feasible within a 6month time frame. Once completed, this notional grid will be able to be downloaded from a shared website and additional features can be added in future releases.

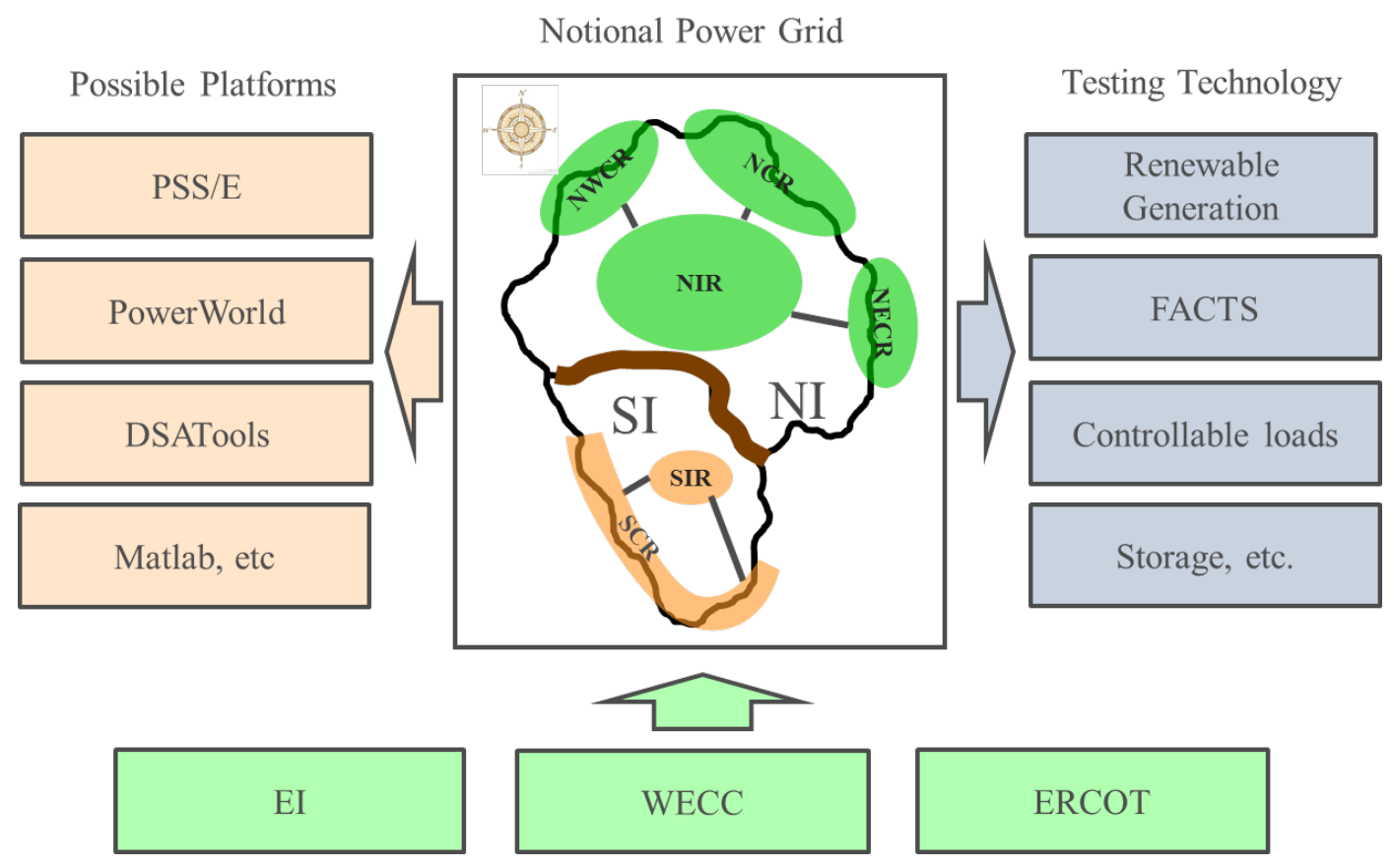

Fig. 1.1. Block diagram of the notional power grid platform

1 Related experiences include the dynamic model construction or conditioning effort of EI, WECC, ERCOT, China Southern Grid, India, and Egypt grids. 


\section{FEATURES TO BE EXHIBITED BY THE NOTIONAL GRID}

The proposed large-scale notional power grid will exhibit the main features of U.S. interconnections, some of which will include but are not limited to:

- A country-scale power grid that covers millions of square miles and a population of hundreds of millions. U.S. operates some of the largest interconnected power grids in the world in terms of generation capacity and covered territories. Therefore, high generation capacity and large service territory are the most significant features the notional power grid will retain.

- Loosely-connected interconnections. The main U.S. grids consist of three looselyconnected interconnections, including the Eastern Interconnection (EI), the Western Interconnection (WI), and the Texas Interconnection, as shown in Fig. 2.1. These interconnections are now connected by only a few transmission lines and there is not much power exchange (compared to the size of each interconnection). The notional power grid model will keep the basic structure of the U.S. power grids.

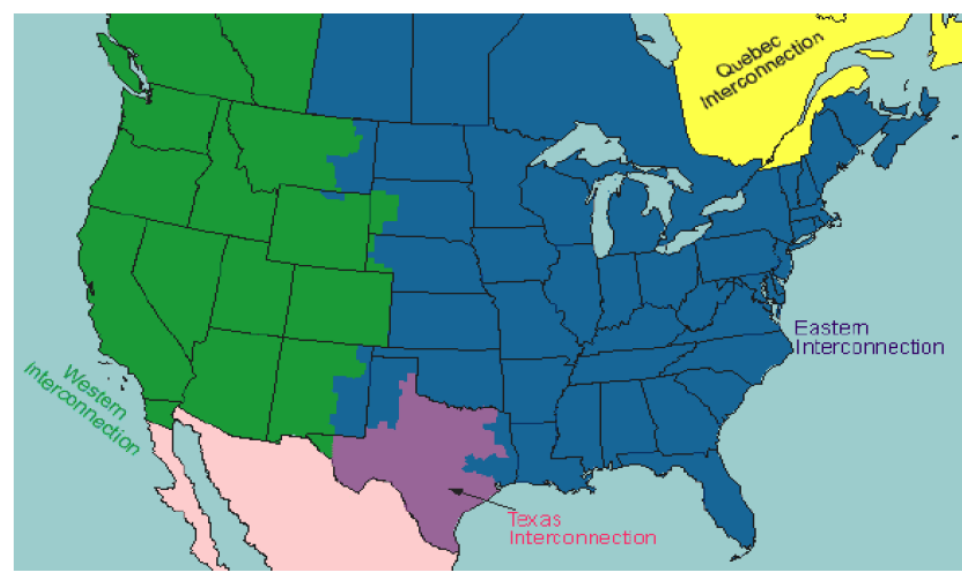

Fig. 2.1. Geographical footprints of the three major interconnections in the U.S. ${ }^{2}$

- Mismatch of generation and load center locations. The locations of load centers in a power grid are mainly decided by population density. Fig. 2.2 shows the population density across the U.S. territory. It is easy to identify several large heavily-populated areas on both eastern and western coasts. On the other hand, the locations of generation hubs are more determined by fuel and cooling water availability, environmental constraints, and real estate availability and cost. This means that the generation sites are usually located remotely from load centers. As a result, the mismatch of generation hub and load centers is common in large countries like U.S. For instance, as shown by Fig. 2.3 , both wind and solar sources are abundant in areas away from load centers in the U.S. Therefore, future renewable generation hubs will not be located near the existing load centers. For the notional power grid, this mismatch of generation hub and load center locations will be reflected.

$2 \mathrm{http}: / /$ energy.gov/oe/services/electricity-policy-coordination-and-implementation/transmissionplanning/recovery-act- 0 


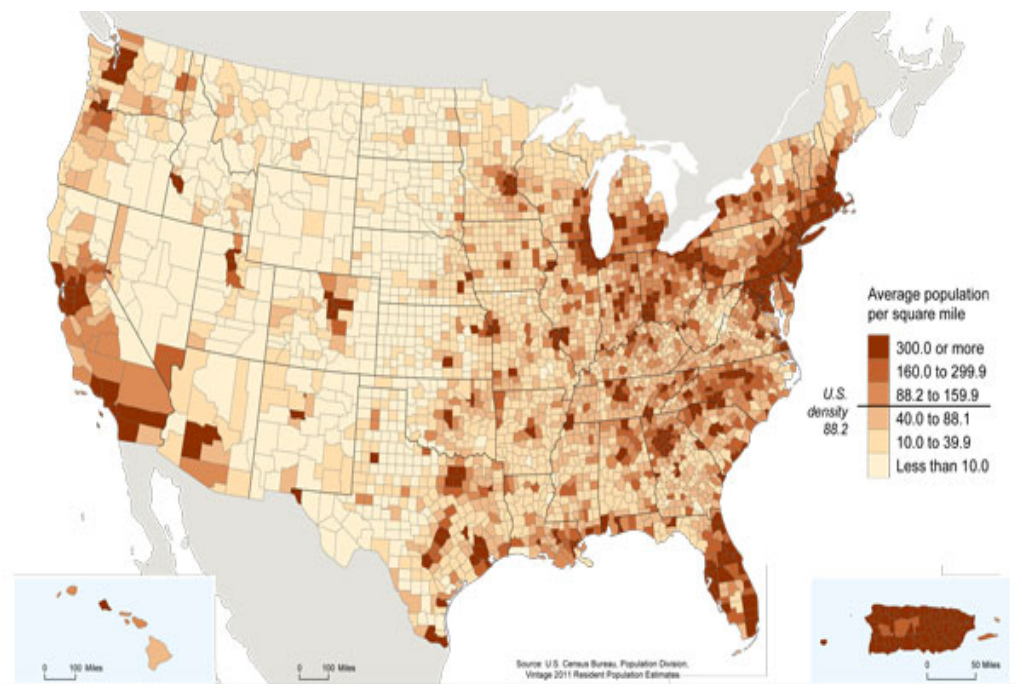

Fig. 2.2. U.S. population density ${ }^{3}$
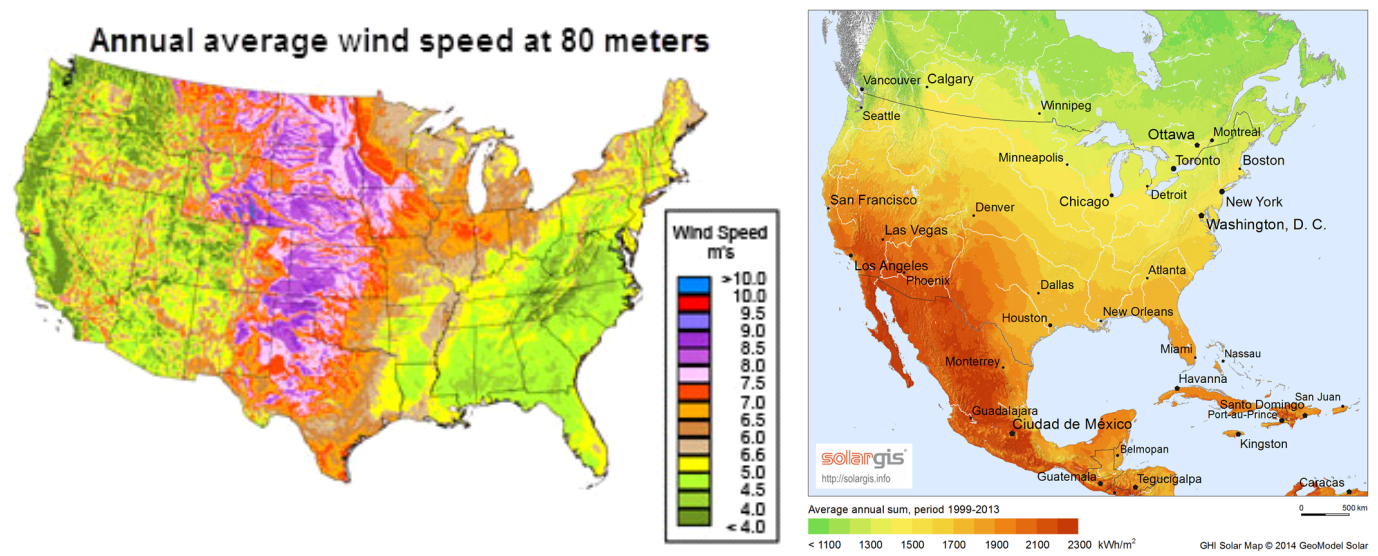

Fig. 2.3. U.S. Wind and solar radiation resources ${ }^{4,5}$

- Long distance and high voltage transmission networks. Due to the mismatch between generation hubs and load center locations, long distance electricity delivery becomes inevitable. Understandably, one important feature of the U.S. power grids is the existence of high capacity, long distance, high voltage transmission networks. Specifically, there are thousands of miles of transmission lines at various voltage levels up to $750 \mathrm{kV}$ in the U.S. Furthermore, because of various benefits of high voltage direct current (HVDC) technology[20][21], many counties including U.S. have been operating many HVDC transmission lines. For U.S. only, several more HVDC transmission lines have been proposed to carry the wind power of Midwest region to load centers. Thus, the notional power grid will feature a high-voltage transmission network, including HVDC transmission lines.

$3 \mathrm{https}: / /$ www.census.gov/popest/data/maps/2011/County-Density-11.html $4 \mathrm{https}: / /$ www.eia.gov/todayinenergy/detail.cfm?id=2470

$5 \mathrm{http}: / /$ solargis.info/doc/_pics/freemaps/1000px/ghi/SolarGIS-Solar-map-North-America-en.png 
- Renewable generation penetration. Electricity generation accounts for much of the carbon emission in the world. Due to the societal pressure to address climate change challenges, countries with large economies are transitioning to the use of renewable resources for electricity generation. Some European countries are leading this process by taking advantage of abundant wind resources and have already achieved a penetration level of $50 \%$ in some areas. U.S. also has ambitious wind development plans in progress (as shown in Fig. 2.4). Therefore, the notional power grid will feature a reasonably high penetration of renewable generation.

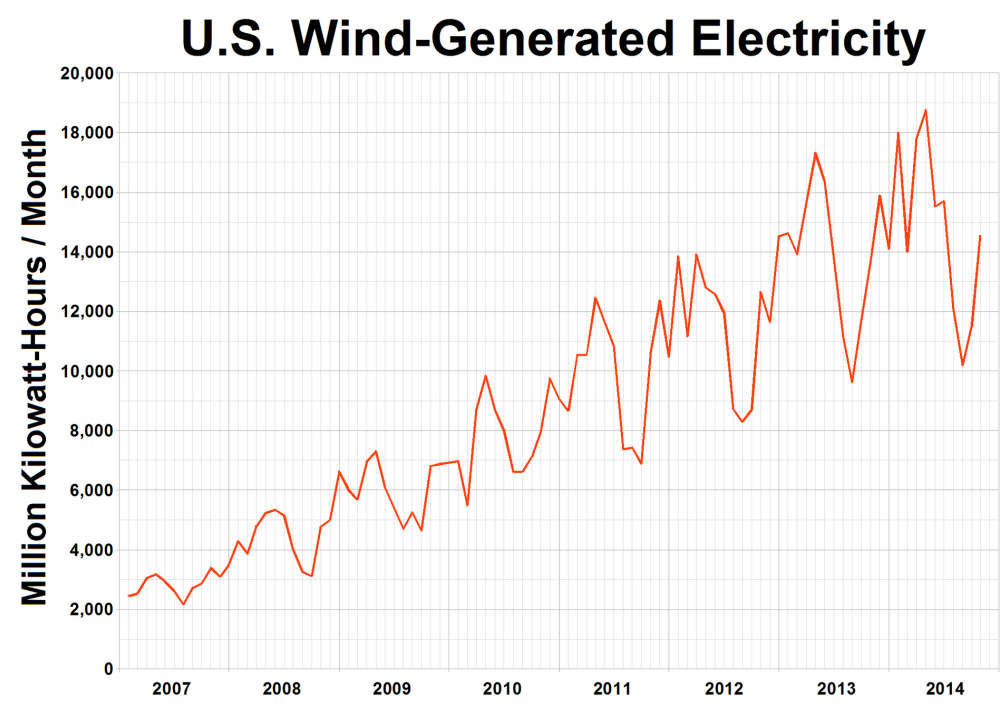

Fig. 2.4. Monthly wind electric power generation in the US (2008-2014) ${ }^{6}$

- Emerging new power electronic control devices. Thanks to the advancement of highcapacity power electronic technology in the past decades, a new generation of power electronic-based system control devices, such as unified power flow controllers [22], static VAR compensators [23], and battery storage devices [24], have been increasingly installed worldwide in power grids for reactive power compensation, power flow control and stability enhancement. The proposed notional grid will include these increasingly common power electronic devices and thus help investigate how the integration of these devices impact power system operation and control.

\subsection{VOLTAGE AND FREQUENCY FEATURES}

Voltage and frequency stability are the top concerns of power system operators. In order to deliver a simulation platform for voltage and frequency stability research, the proposed notional power grid model will possess representative voltage and frequency features of U.S. power grids.

- Representative frequency features: power grid frequency reflects the balance of generation and demand within a system and is usually considered as a universal parameter across the entire power grid during normal conditions. That means different locations of inter-connected power grids share the exact same frequency at the same time if there is no disturbances occurring. Furthermore, the actual power grid frequency in

6 https://en.wikipedia.org/wiki/Wind_power_in_the_United_States 
U.S. grids is maintained within a narrow range around $60 \mathrm{~Hz}$ most of the time. That is accomplished by carefully designed and strictly implemented frequency regulation policies. Additionally, the frequency response of a power system after disturbances is a natural response of all power system components and is considered the most significant indicator of power system frequency stability. Therefore, typical frequency response profiles of U.S. grids (as shown by the well-known ABC curve in Fig. 2.5) will be replicated by the proposed notional power grid. It should be noted that frequency response characteristics are slightly different among three U.S. interconnections due to their different capacities, generation mixes, and regulation policies. Those differences will also be reflected by different regions of the notional power grid.
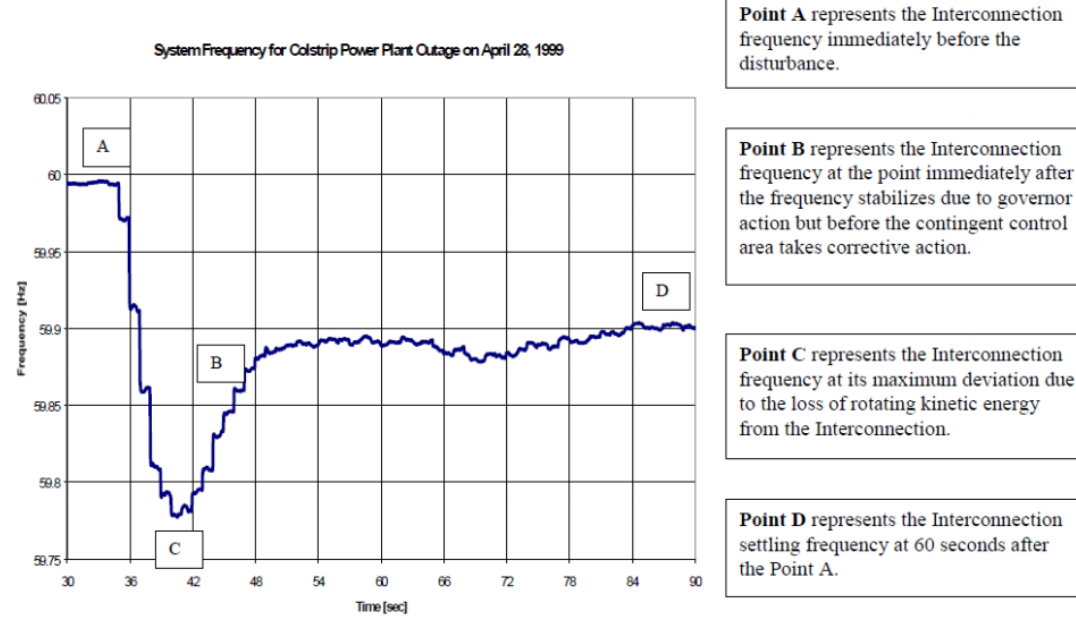

Point B represents the Interconnection frequency at the point immediately after the frequency stabilizes due to governor action but before the contingent control area takes corrective action.

Point $\mathrm{C}$ represents the Interconnection frequency at its maximum deviation due to the loss of rotating kinetic energy

from the Interconnection.

Point $D$ represents the Interconnection settling frequency at 60 seconds after the Point A.

Fig. 2.5. Typical frequency response in the U.S. power grids ${ }^{7}$.

- Representative voltage features: Unlike frequency, voltage is more of a local variable and related closely to reactive power. Generally, voltage magnitude during normal operation conditions is required to be between 0.95 and 1.05 p.u. During dynamics, the voltage magnitude may fall as low as $0.3-0.5$ p.u, but usually recovers to the nominal value quickly. Generators with automatic voltage regulation, transformer tap changer, and reactive power compensation devices work together to achieve that [25]. In order to replicate these voltage features, the notional power grid will have similar voltage regulation devices and strategies.

- Load models are important: Load modeling can significantly impact both frequency and voltage features of a power grid model [26]. For example, fault induced voltage recovery delay, which usually occurs in areas with heavy induction motor load, is a severe threat to voltage stability [27] [28]. Hence, this phenomenon will be reflected in a part of the notional power grid by having a large penetration of induction motor loads.

\subsection{STEADY-STATE POWER FLOW AND DYNAMIC CHARACTERISTICS}

Power flow calculations reflect the steady state operation of a power system and provide initial states for dynamic simulations. Therefore, the notional power grid power flow model will be built as the

7 http://www.nerc.com/docs/pc/FRI_Report_10-30-12_Master_w-appendices.pdf, 2012. 
first step. Key aspects of the power flow model include:

- The concept of a balancing authority will be considered in the power flow model of the notional grid, which means generation and load are largely balanced within each balancing authority and the power exchange between different balancing authorities will be relatively small.

- Continuous power flow study is a basic method for voltage stability study [25]. Hence, certain parts of the notional grid model will be designed in a way that voltage stability study can be easily carried out.

- Due to the nonlinear nature of power flow calculations, numerical methods will be employed to obtain a solution that is within an acceptable tolerance. This tolerance will be carefully selected to achieve a balance between accuracy and convergence. Current industry practice of solution accuracy will be used as guilelines here.

- Visualizing the power flow calculation results is another important issue of power flow study. A one-line diagram and contour map may be used for result visualization (some software tools already have such functions).

- Notional GPS coordinates will be provided for all physical components.

Dynamic characteristics of the notional grid will be roughly divided into two categories, small-signal and transient. For the small-signal dynamics, the notional grid will be designed to reflect real-world inter-area oscillation in the U.S. power grid (as shown in Fig. 2.6), which has been monitored by the UTK/ORNL Frequency Monitoring Network (FNET/GridEye) since 2004 [29]. As with large-signal dynamics, the transient dynamic responses of the notional grid will also be designed to reflect realworld transient responses in the U.S. power grid. These, too, will be based on transient behaviors observed with the FNET/GridEye system over the last ten years.

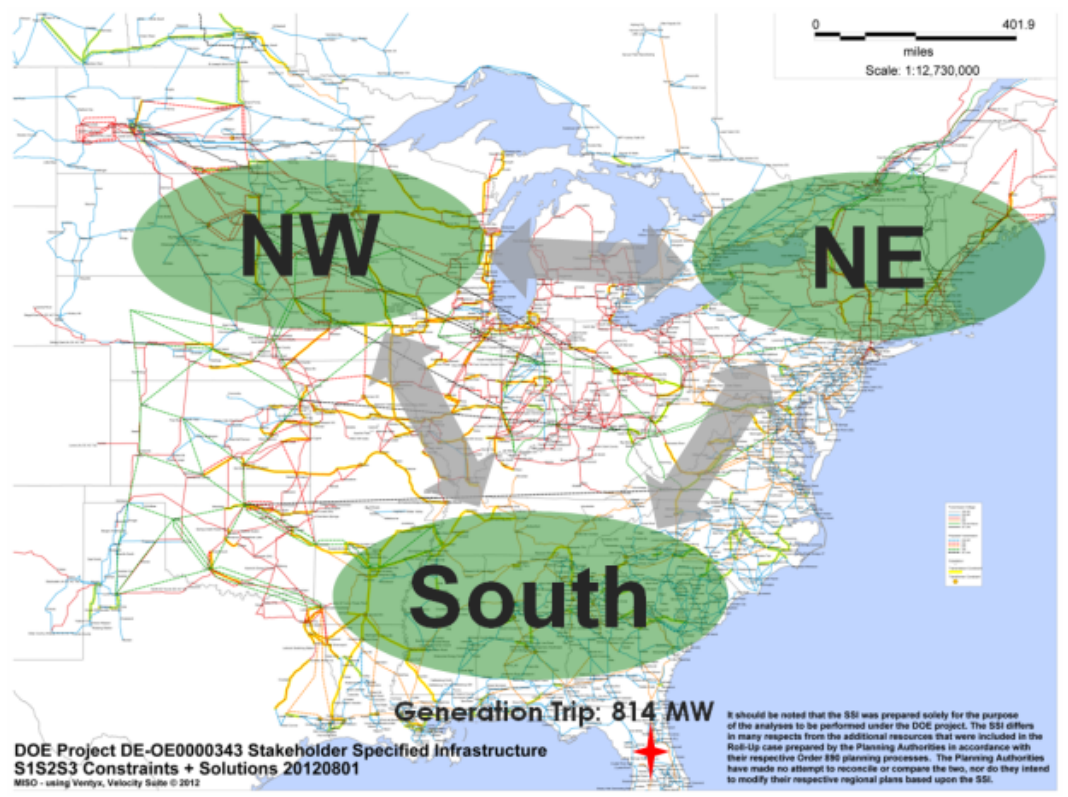

Fig. 2.6. Main inter-area oscillation regions in the U.S. EI system. 


\subsection{DISTRIBUTION SYSTEM REPRESENTATION}

The proposed notional power grid should not be limited only to transmission level studies. Considering that future renewable generation development will be mostly located at the distribution level, distribution system modeling in the proposed model will be extremely beneficial. However, modeling distribution networks across the entire power grid will be avoided since it will dramatically increase the model complexity and slow down the simulation speed. Furthermore, doing so is not necessary because the study and operation of a particular distribution system does not involve others. Thus, to provide an efficient and standard platform for distribution system studies, some IEEErecommended distribution models will be incorporated at certain nodes of the notional grid's transmission backbones. As shown by Table 2.1 below, the number of busses in IEEE-recommended distribution models range from 16 to 119 and the voltage level can be as low as $11 \mathrm{kV}$ [30]. These types of distribution models will be incorporated at select areas/regions with different levels of renewables, controllable loads, and flexisible AC transmission (FACTS) devices in the notional grid in order to achieve an optimum balance between studying new devices and keeping the model solvable. In this way, the study team can take advantages of the IEEE fully-developed distribution models without unnecessarily increasing the complexity of the notional model.

Table 2.1. Select IEEE-recommended distribution models in literature

\begin{tabular}{cccccc}
\hline & 16 Bus & 30 Bus & 33 Bus & 94 Bus & 119 Bus \\
\hline Nominal voltage & $23 \mathrm{kV}$ & $11 \mathrm{kV}$ & $12.66 \mathrm{kV}$ & $11.4 \mathrm{kV}$ & $11 \mathrm{kV}$ \\
\hline No. of sectionalizing branches & 13 & 29 & 32 & 83 & 118 \\
\hline No. of tie switches & 3 & 1 & 5 & 13 & 15 \\
\hline
\end{tabular}

\subsection{BASE CASES MODELED}

In today's power system transmission planning practice, there is a need to plan the system at a variety of load levels and conditions. In this project, only one basic case will be built as the first step. More cases such as summer peak, shoulder season, and winter peak cases will be built if necessary in the future. One of the most significant applications of this notional grid platform will be investigating the impact of renewable power on the U.S. power grid, therefore, a high renewable version of the basic case will also be built. Furthermore, energy storage, demand side management, FACTS device, and HVDC lines will be considered in this scenario.

More detailed information of these two cases are provided in the next chapter.

\subsection{COMPARISON OF THE NOTIONAL SYSTEM VERSUS THE IEEE 118-BUS SYSTEM}

To illustrate the significant benefits of the proposed notional power grid model, a comparison of the proposed model and IEEE 118-bus system was carried out, the results of which are given in Table 2.2. It can be seen that, besides the mere size, the notional power system model has many more significant features than IEEE 118-bus system. 
Table 2.2. Comparison of IEEE 118-bus system and notional Atlantis system.

\begin{tabular}{|c|c|c|c|}
\hline & & IEEE 118-bus system & Notional Grid \\
\hline \multirow{3}{*}{ Size } & Number of generators & 41 & $1000-1500$ \\
\hline & Number of busses & 118 & $6,000-10,000$ \\
\hline & Voltage levels & Up to $277 \mathrm{kV}$ & Up to $750 \mathrm{kV}$ \\
\hline \multirow{10}{*}{$\begin{array}{l}\text { Features and } \\
\text { functions }\end{array}$} & Transmission system modeling & Yes & Yes \\
\hline & Distribution system modeling & No & Yes \\
\hline & $\begin{array}{l}\text { Renewable generation } \\
\text { modeling }\end{array}$ & No & Yes \\
\hline & FACTS modeling & No & Yes \\
\hline & HVDC modeling & No & Yes \\
\hline & Storage modeling & No & Yes \\
\hline & Controllable load modeling & No & Yes \\
\hline & Protection modeling & No & Yes \\
\hline & Inter-area oscillation modes & Yes (but limited) & Yes \\
\hline & Local oscillation modes & Yes & Yes \\
\hline \multirow{9}{*}{$\begin{array}{l}\text { Feasible } \\
\text { studies }\end{array}$} & Steady-state power flow study & $\begin{array}{l}\text { Only good for concept } \\
\text { verification }\end{array}$ & $\begin{array}{l}\text { Large system } \\
\text { test and demo }\end{array}$ \\
\hline & Frequency support study & $\begin{array}{l}\text { Only good for concept } \\
\text { verification }\end{array}$ & $\begin{array}{l}\text { Large system } \\
\text { test and demo }\end{array}$ \\
\hline & Frequency/angle stability study & $\begin{array}{l}\text { Only good for concept } \\
\text { verification }\end{array}$ & $\begin{array}{l}\text { Large system } \\
\text { test and demo }\end{array}$ \\
\hline & Voltage stability study & $\begin{array}{l}\text { Only good for concept } \\
\text { verification }\end{array}$ & $\begin{array}{l}\text { Large system } \\
\text { test and demo }\end{array}$ \\
\hline & Small-signal stability study & $\begin{array}{l}\text { Only good for concept } \\
\text { verification }\end{array}$ & $\begin{array}{l}\text { Large system } \\
\text { test and demo }\end{array}$ \\
\hline & FACTS/HVDC/Storage study & Not directly feasible & $\begin{array}{l}\text { Large system } \\
\text { test and demo }\end{array}$ \\
\hline & Controllable load study & Not directly feasible & $\begin{array}{l}\text { Large system } \\
\text { test and demo }\end{array}$ \\
\hline & Protection study & Not directly feasible & $\begin{array}{l}\text { Large system } \\
\text { test and demo }\end{array}$ \\
\hline & Renewable integration study & Not directly feasible & $\begin{array}{l}\text { Large system } \\
\text { test and demo }\end{array}$ \\
\hline
\end{tabular}




\section{SIMULATION ENVIRONMENT}

\subsection{COMMERCIAL SOFTWARE}

A software environment will be chosen as the first step in building the simulation environment. This decision will be based on providing value to a broad-based audience of researchers and commercial developers as well as providing flexibility for incorporating new power system components/control technologies. The most popular simulation tools are briefly compared below in Table 3.1.

Table 3.1. Simulation environment comparison.

\begin{tabular}{|c|c|c|}
\hline & Pros & Cons \\
\hline PSS/E and PSLF & $\begin{array}{l}\text { - Widely used in academia and } \\
\text { industry } \\
\text { - } \quad \text { Proven to handle a large-scale } \\
\text { power grid model } \\
\text { - } \quad \text { Automated process using Python }\end{array}$ & 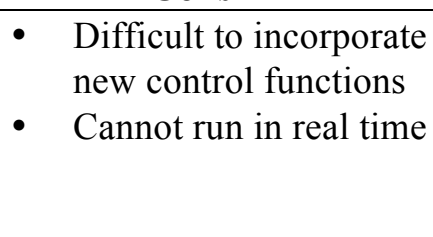 \\
\hline DSATools & $\begin{array}{ll}\text { - } & \text { Full power system analysis } \\
\text { package } \\
\text { - } & \text { Compatible with PSS/E format } \\
\text { - } & \text { Potential to run real-time } \\
\text { simulation }\end{array}$ & $\begin{array}{l}\text { No interactive version } \\
\text { published yet }\end{array}$ \\
\hline PowerWorld & $\begin{array}{ll}\text { - } & \text { Compatible with PSS/E format } \\
\text { - } & \text { Good information management } \\
\text { - } & \text { Good visualization tool } \\
& \text { Potential to run real-time } \\
& \text { simulation } \\
\end{array}$ & $\begin{array}{l}\text { - } \quad \text { Difficult to incorporate } \\
\text { new control functions }\end{array}$ \\
\hline ePHASORsim & $\begin{array}{ll}\text { - } & \text { Real-time simulation } \\
\text { - } & \text { Hardware-in-the-loop capability }\end{array}$ & $\begin{array}{l}\text { Lacks basic models } \\
\text { - lacks a track record of } \\
\text { actual use cases. }\end{array}$ \\
\hline
\end{tabular}

Since PSS/E is the most widely used dynamic simulation tool in the electric power industry and academia, the notional power grid will be primarily driven by $\mathrm{PSS} / \mathrm{E}^{8}$.

\subsection{WIND AND SOLAR MODELS}

The rationale for selecting wind and solar models is presented in this section. The major commercial software vendors mentioned in the previous section have all built some wind and solar models for use in their simulation environment. For instance, PSS/E has all four types of basic wind generator models included in the model library [31]; these models have been widely employed in research to investigate the impact of wind and solar generations on power system stability. For studies of the transmission system, existing models for wind and solar generators in PSS/E are sufficient ${ }^{9}$. These models are actually aggregated plant models that were designed for transmission level dynamic simulations, so their use in this model is consistent with their intended purpose. For studying the effects on the transmission system of novel control systems for wind and solar plants, the generic models provided in the PSS/E environment will not suffice, so user-defined models of the novel

8 It can be converted into DSATools and PowerWorld environments since these are both compatible with PSS/E format.

9 The wind or solar plant level study is not the focus. 
control systems will need to be developed. While the notional power grid platform will accommodate this, modeling the novel controls is outside the scope of this project.

\subsection{PROTECTION SYSTEMS}

Protection devices in a power grid detect problems with power system components and isolate these components. This is done to minimize equipment damage, improve system stability, and ensure personnel safety [25]. Therefore, they are important to power system operation and security. In order to facilitate the protection study, the notional grid model will provide for modeling of protection devices.

Generic protection models are not intended to exactly represent any particular manufacturers' relay model [31] or any particular utility's protection philosophy. Instead, these models represent general principles of protection relays and general strategies used for calculating relay settings and coordinating protection coverage. Because they suffice for large-scale system analysis (as opposed to specific relay coordination studies), generic protection models will be utilized in the notional grid model.

Generic protection models include transmission line protection, under frequency/voltage load shedding, and machine/transformer protection. Transmission line protection can be complicated and needs coordination within a power grid. Therefore, transmission line protection will be modeled. However, only a certain region instead of the entire power grid's protection systems will be modeled for simplicity. Again, user-defined models will be needed if any new protection device or scheme is developed (outside the scope of this platform).

\subsection{PLANNING SCENARIOS (PENETRATION OF RENEWABLES, STORAGE, CONTROLLED LOADS, AND FACTS)}

The process of defining scenarios considers a lot of factors, including level of conventional generation, renewable generation, storage, conventional loads, controllable loads, and FACT devices.

Scenario 1 will be a simulation scenario that represents the current U.S. electric grid. Modeling this state is the first step, since the renewables, storage, controllable load and FACTs levels are relatively low. Scenario 2 will be a scenario that represents the 2030 U.S. power grid. This scenario will be based on the DOE Energy Information Administration projection [32]. These two scenarios are presented below in Table 3.2.

For Scenario 1, no storage, controllable loads, or FACTS devices will be modeled, wind penetration level is around 5\%, and solar penetration is less than 1\%. For Scenario 2 (Year 2030), wind penetration will be modeled at $20 \%$, solar penetration will be at $5 \%$ as will be storage and FACTS. Controllable loads will be modeled at $10 \%$.

It should be noted that the notional grid platform will include a toolset for use by future users. Using these tools, users will be able to quickly adjust the levels of storage, FACTS, and controllable loads, thus giving the simulation scenarios much more flexibility. 
Table 3.2. Scenario information of the notional grid model.

\begin{tabular}{|c|c|c|c|c|c|c|}
\hline \multirow[t]{2}{*}{ Scenario } & \multicolumn{3}{|c|}{$\begin{array}{l}\text { Level of main renewable } \\
\text { generation } \\
{ }^{1} \\
\text { (percentage of generation } \\
\text { capacity) }\end{array}$} & \multirow[t]{2}{*}{$\begin{array}{c}\text { Storage } \\
\text { (percentage of } \\
\text { generation } \\
\text { capacity) }\end{array}$} & \multirow[t]{2}{*}{$\begin{array}{c}\text { Controllable } \\
\text { load } \\
\text { (percentage of } \\
\text { total load) }\end{array}$} & \multirow[t]{2}{*}{$\begin{array}{l}\text { FACTS } \\
\text { (percentage of } \\
\text { generation } \\
\text { capacity) }\end{array}$} \\
\hline & Hydro & Wind & Solar & & & \\
\hline 1 & $7 \%$ & $5 \%$ & $<1 \%$ & $0 \%$ & $0 \%$ & $0 \%$ \\
\hline 2 & $\sim 5 \%$ & $\sim 20 \%$ & $\sim 5 \%$ & $\sim 5 \%$ & $\sim 10 \%$ & $\sim 5 \%$ \\
\hline 1. & $\begin{array}{l}\text { use of } \\
\text { jioma }\end{array}$ & $\begin{array}{l}\mathrm{r} \text { relat } \\
\text { ill be }\end{array}$ & $\begin{array}{l}\text { low } \mathrm{p} \\
\text { cted. }\end{array}$ & ation leve & energy sou & h as geothe \\
\hline
\end{tabular}

\subsection{METHODS USED TO VALIDATE THE NOTIONAL GRID}

Though the notional grid is not intended to model any specific power grid now in service, it still needs to be validated in order to be reasonably assured that the performance of new technologies observed on the notional grid reflect the performance in an actual implementation. Methods for validating the notional grid are discussed in this section.

- For validating power flow calculation results, mismatches of system P and Q after solving the power flow equations will be used as an indicator of power flow convergence and accuracy ${ }^{10}$. Furthermore, different power flow calculation methods, such as NewtonRaphson and Gauss-Seidel methods, will be utilized to solve the same power flow case to verify its convergence.

- For dynamic simulation cases, a successful initiation process is necessary. Any unexpectedly large numerical errors during the initiation process usually indicate the existence of incorrect data or ill-conditioned dynamic models. As a result, numerical errors during the initiation process will be used to locate problems. For example, a reported "suspect state" within a generator model usually indicate a wrong generator dynamic parameter.

- Batch of dynamic simulations. Converged power flow and successful dynamic simulation initiation can only gurantee the availability of a numeral solution, not its correctness. So a selected set of dynamic simulations, including different types and locations of disturbances, will be carried out and their results will be plotted and verified against each other.

- Validation by real measurements. Some features of the model can be validated by real synchrophasor measurements. For instance, the notional grid is expected to have two or three inter-area oscillation modes similar to the U.S. power grids' for the purpose of small-signal stability study. After the notional grid is built, it will be tuned to have the similar oscillation modes to the ones monitored by real measurements.

10 PSS/E Version 32 User's Manual 



\section{SYSTEM PARAMETERS}

In this chapter, the notional power grid model topologies and parameters will be defined.

\subsection{DEFINE SYSTEM SIZE: TOPOLOGY \& REGIONS, VOLTAGE LEVEL, MW AND MVAR}

As mentioned in Chapter 2, the notional grid will be a large-scale interconnected power grid that covers a territory of millions of square miles and a population of hundreds of millions. To avoid any confidentiality or security issues, the notional power grid will be designed to cover the imaginary Atlantis continent. This approach provides great flexibility to study how new technologies might operate when deployed in an operating power grid. As shown by the world map below (Fig. 4.1), the imaginary continent of Atlantis will have similar latitudes as the continental U.S.

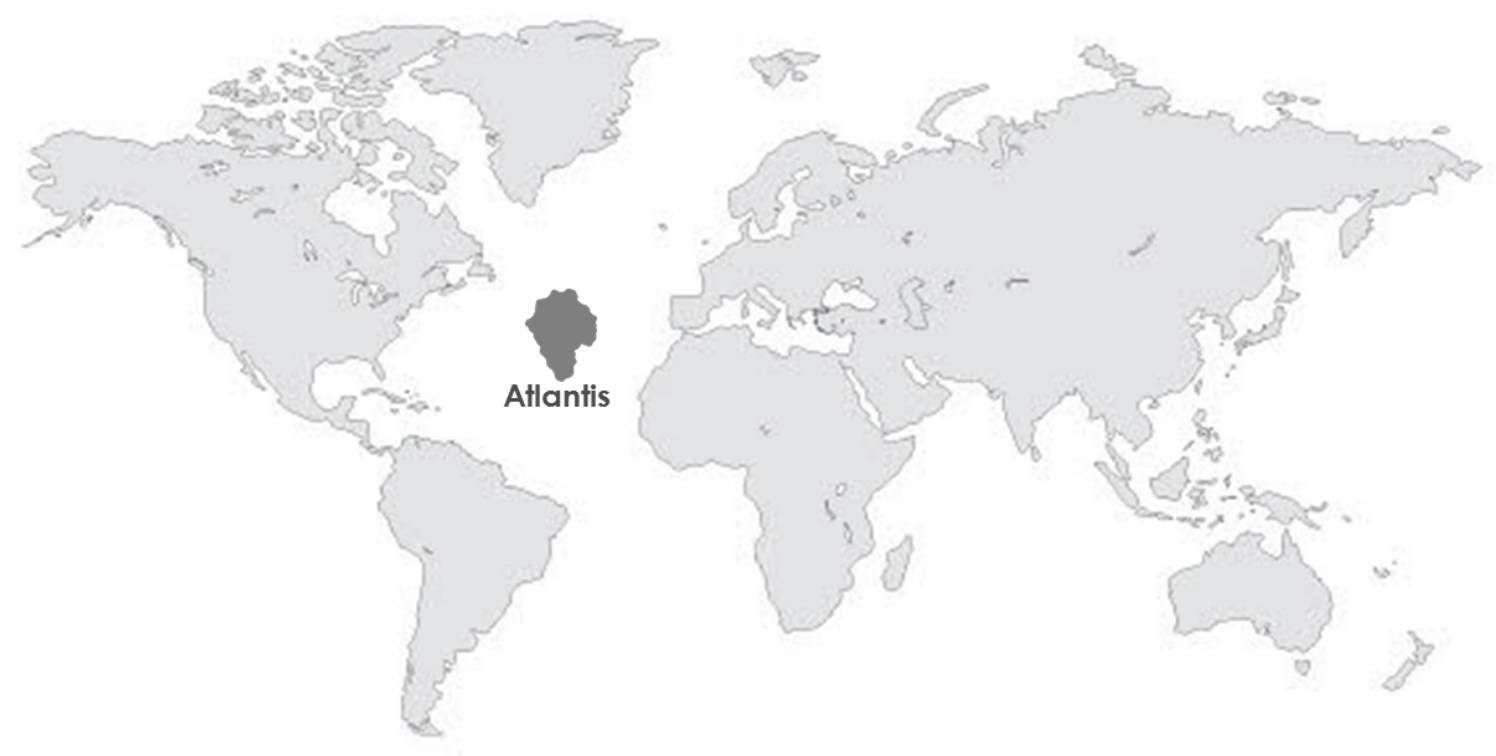

Fig. 4.1. Imaginary location of Atlantis continent in the world.

Based on some legends [33], a geographic map of the imaginary Atlantis continent is drawn in Fig. 4.2. Considering this geographic layout and the need to divide the notional grid into regions, some metropolitan areas were created and labeled. Reasonably, large metropolitan areas lie on the coasts and mostly at the river delta areas. Some small metropolitan areas were also made up to represent smaller load centers. While these labeled metropolitan areas indicate the location of large and small load centers, there are smaller loads spreading over the entire Atlantis territory. All the load buses will be given corresponding GPS coordinates so that a comprehensive load map will be available. 


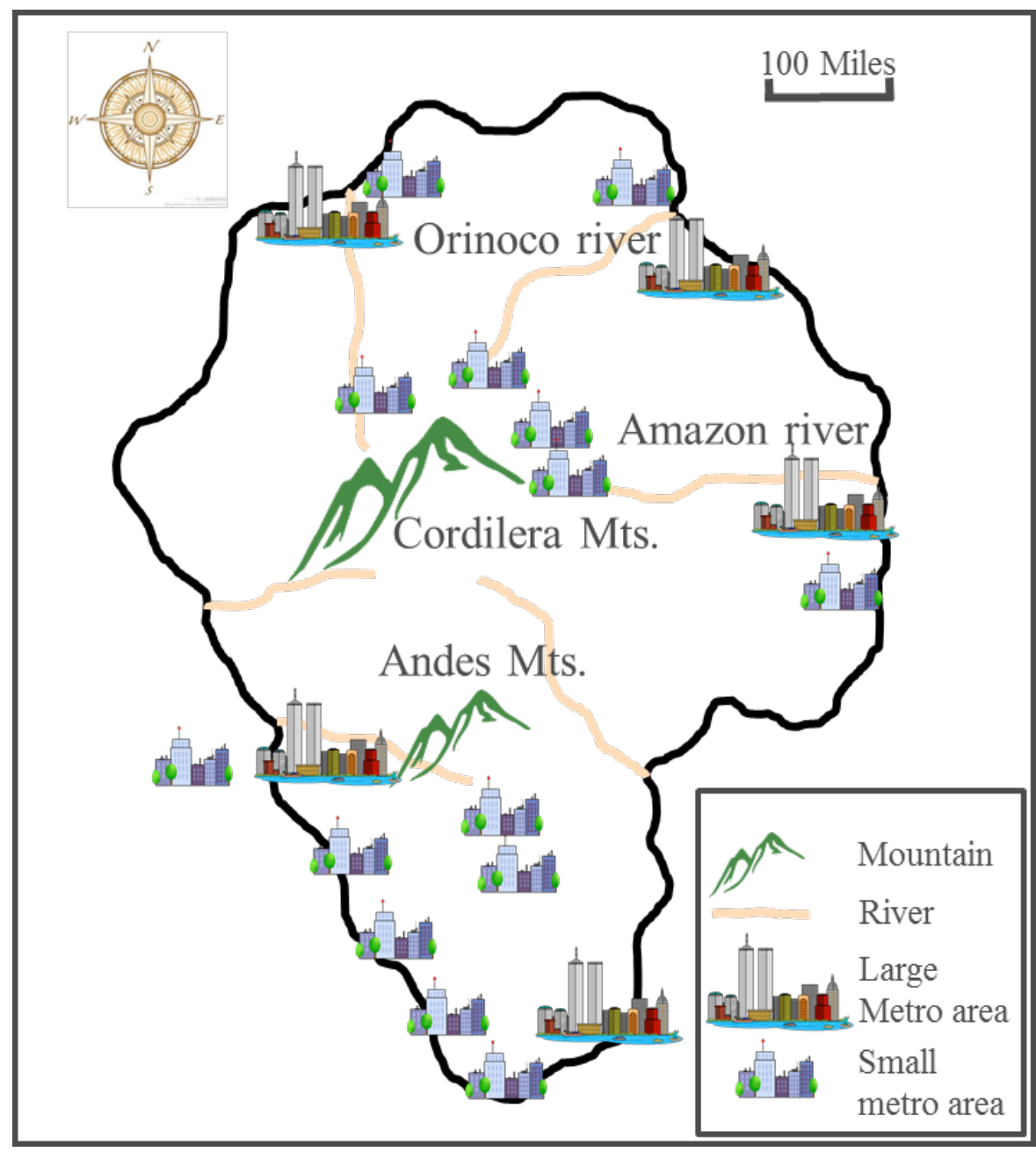

Fig. 4.2. Geographic map of the imaginary Atlantis continent.

As discussed in Chapter 2, the notional power grid will consist of several loosely connected interconnections similar to the U.S. grids. To retain this feature, the Atlantis power grid will include North and South, two main interconnections, as shown in Fig. 4.3. These two interconnections will be loosely connected by HVDC transmission lines (discussed later) and their power exchange will be relatively small compared to their own generation capacities. Specifically, within the North Interconnection, there will be three regions, including Northwest coastal region (NWCR), North coastal region (NCR), and Northeast coastal region (NECR), along the coast that represent the three large metropolitan areas in Fig. 4.2. Additionally, there will be one bulk region in the middle of the North Interconnection, which will be referred to as North inland region (NIR) in this project. The North Interconnection layout was designed to retain the basic layout of the U.S. Eastern Interconnection.

For the South Interconnection, there will be a strip-shaped region along the coast (referred to as the Southern coastal region, SCR), including Southeastern coastal region (SECR) and Southwestern coastal region (SWCR), and a South inland region (SIR), the two of which will form a ring. This layout is intended to replicate the inter-area oscillation characteristics of the U.S. Western Interconnection. 


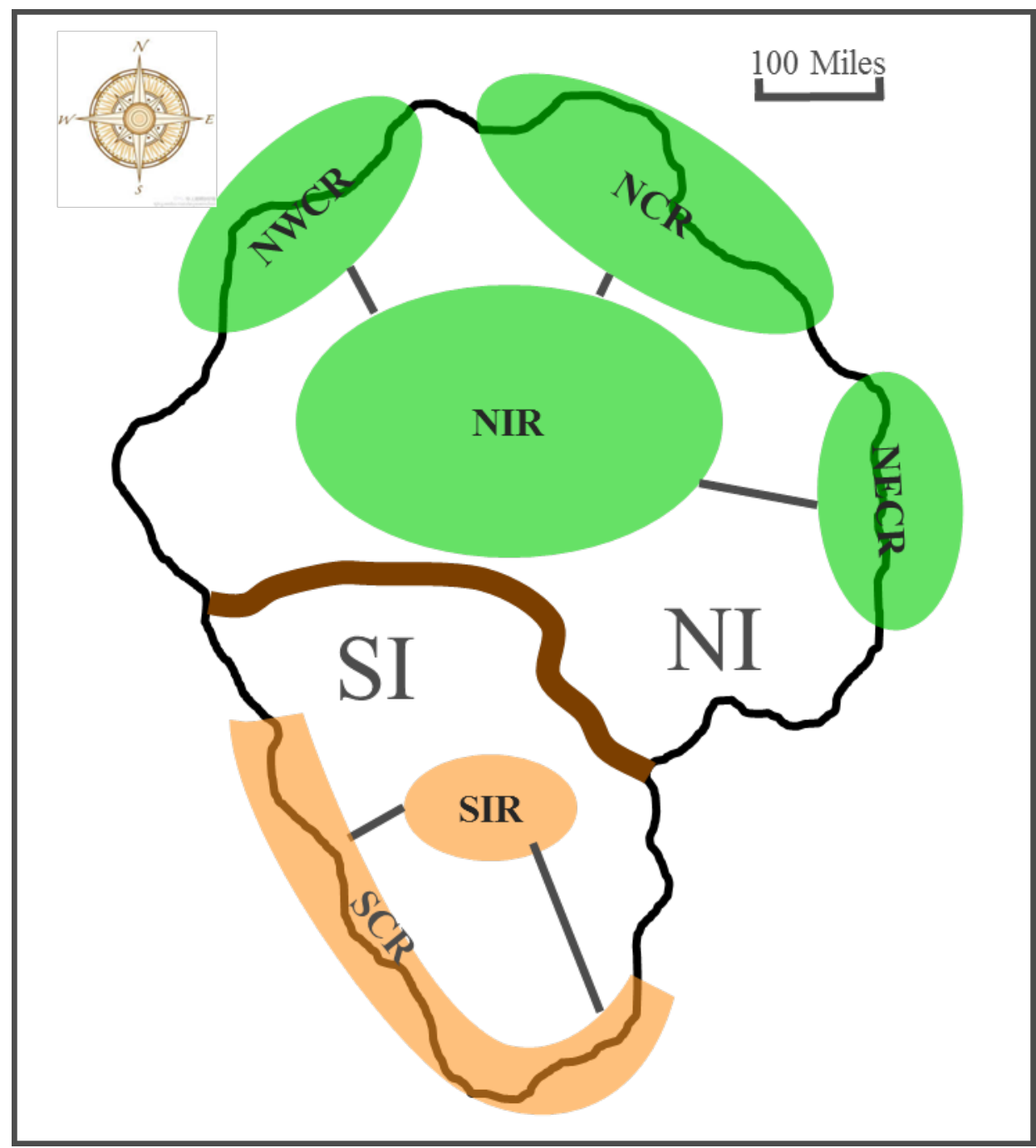

Fig. 4.3. Basic topology and regions of notional Atlantis grid.

The notional grid will have similar voltage levels to the U.S. grid and about one fourth of its generating capacity. Preliminary values for the generation capacities, voltage levels and number of busses for each Atlantis interconnection are presented in Table 4.1.

Table 4.1. Generating capacity, number of busses, and voltage levels for each interconnection.

\begin{tabular}{ccccc}
\hline \multirow{2}{*}{$\begin{array}{c}\text { Inter- } \\
\text { connecton }\end{array}$} & Generating capacity $(\mathbf{G W})$ & Number of & \multicolumn{2}{c}{ Voltage levels } \\
\cline { 2 - 3 } \cline { 5 - 5 } & Base Case & Busses & Transmission & Distribution \\
\hline North & $120 \sim 200$ & $4,000-8,000$ & $230-750 \mathrm{kV}$ & $11-69 \mathrm{kV}$ \\
\hline South & $30 \sim 50$ & $1,000-2,000$ & $115-500 \mathrm{kV}$ & $11-69 \mathrm{kV}$ \\
\hline \multirow{2}{*}{ Total } & $150 \sim 250$ & $5,000-$ & $750,500,345,230,115,69,34,11 \mathrm{kV}$ \\
etc.
\end{tabular}

From the table above, the generation capacities of the North and South Interconnections are preliminary set to be up to 200 and $50 \mathrm{GW}$. These numbers are driven by two main considerations: first, generation capacity and number of busses of this Atlantis grid should be large enough to make it a large-scale interconnected power system that demonstrates complicated dynamics; second, the 
number of busses should be small enough to achieve numerical stability and acceptable simulation speed.

\subsection{WIND, SOLAR, OFF-SHORE WIND SIZE AND ALLOCATION}

By looking at the Atlantis map, it is clear that the imaginary Atlantis continent is home to abundant renewable generation sources. Specifically, this continent was imagined to have good solar radiation in the South due to the low latitude and plentiful wind and hydro sources around Cordilera Mountains. Moreover, as is the case in North Europe and Northeast U.S., off-shore wind farms will be built, which will be connected to the main grid via HVDC undersea lines. Based on these assumptions, the major wind, solar, hydro, and off-shore wind locations are roughly labeled in Fig. 4.4.

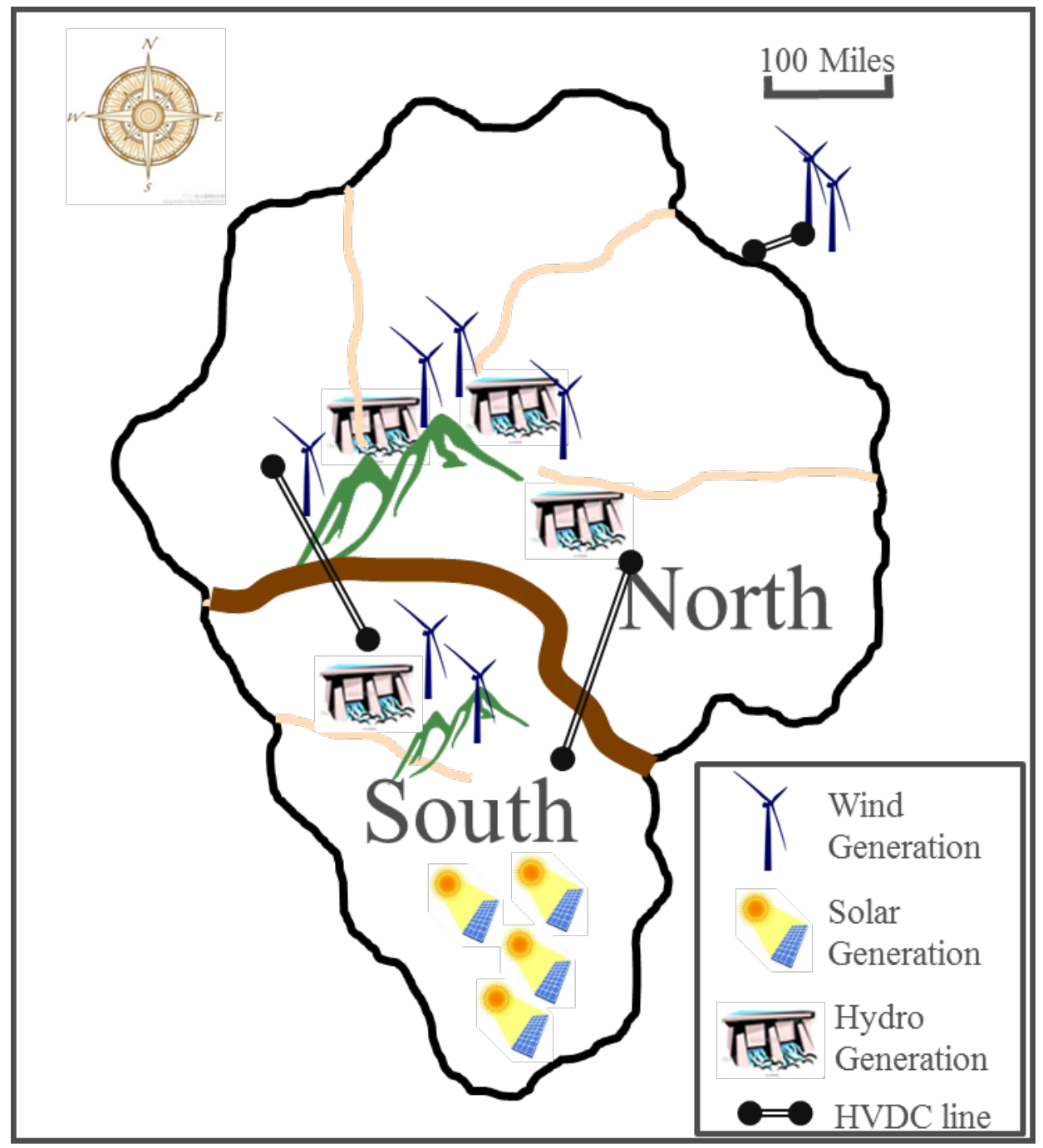

Fig. 4.4. Location of renewable generation on the Atlantis grid.

\subsection{LOCATION OF MAJOR GENERATION AND LOAD CENTERS}

Mismatch of major generation and load center locations is one basic feature of the U.S. power grids. 
To reflect this feature, the major generation and load centers will not overlap in the notional Atlantis grid (Fig. 4.5). As shown in Fig. 4.2, the most populated cities lie on the coastlines and are close to the river deltas. On the other hand, the major generation centers are close to primary energy sources. Thus, the major generation centers in the notional Atlantis grid will be located close to coal, hydro, or wind sources, which are far from the coastlines. Since most of the generation and load centers are not in close proximity, high voltage and long distance transmission lines will be used to connect them.

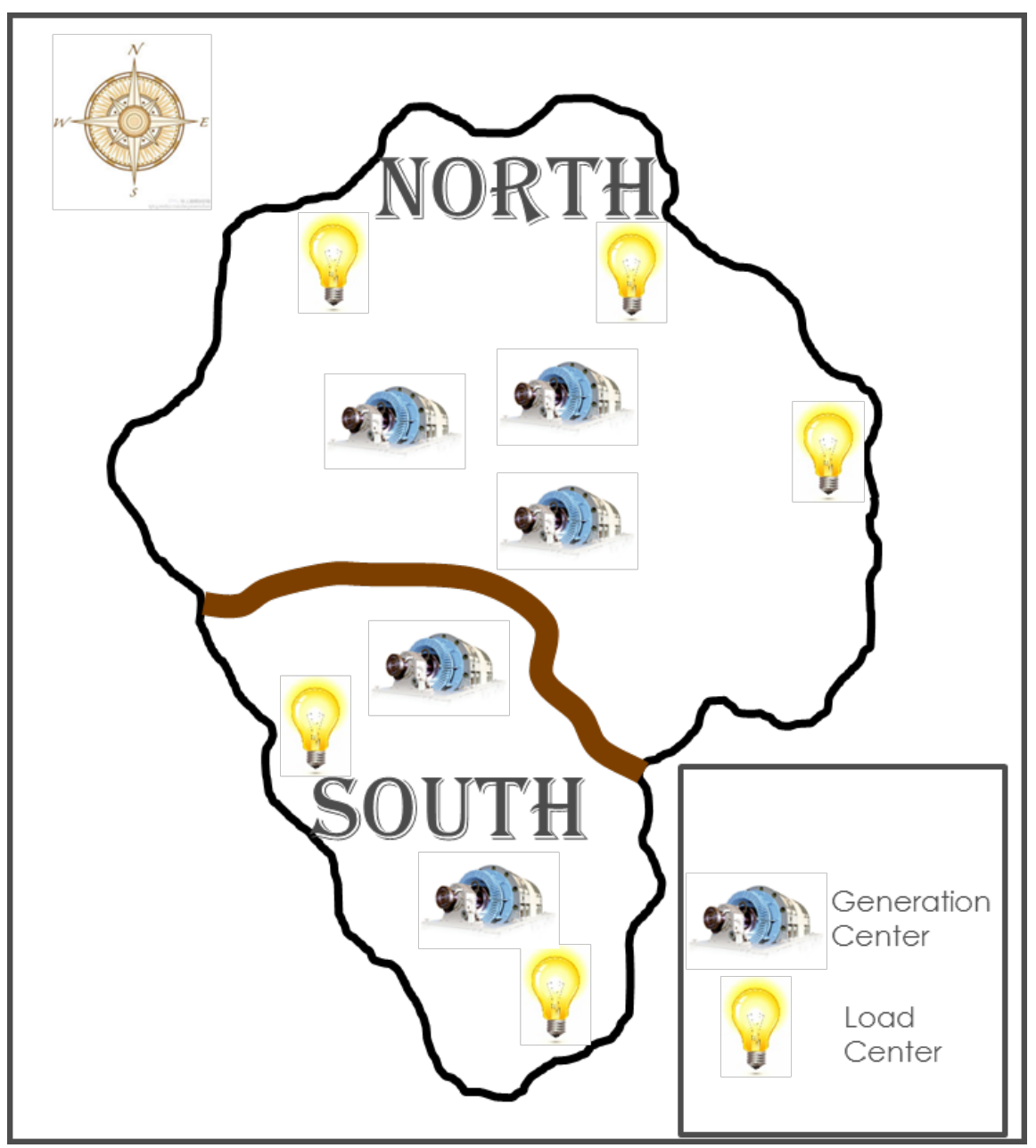

Fig. 4.5. Major generation and load centers in the notional Atlantis grid.

\subsection{FACTS, STORAGE, AND HVDC SIZE AND ALLOCATION}

Since the North and South Interconnections are to be loosely connected, HVDC transmission lines will be utilized to connect them to one another. As shown in Fig. 4.6, the two interconnections will be connected by two HVDC lines.

Energy storage and FACTS devices will be located close to generation and load centers. Furthermore, according to some research [34] [35], renewable generation stations need storage and FACTS devices to help their operation as well. Therefore, the locations of energy storage and FACTS devices will be distributed accordingly in Fig. 4.6. The size of FACTS and energy storage will be scaled according to Table 3.2. 


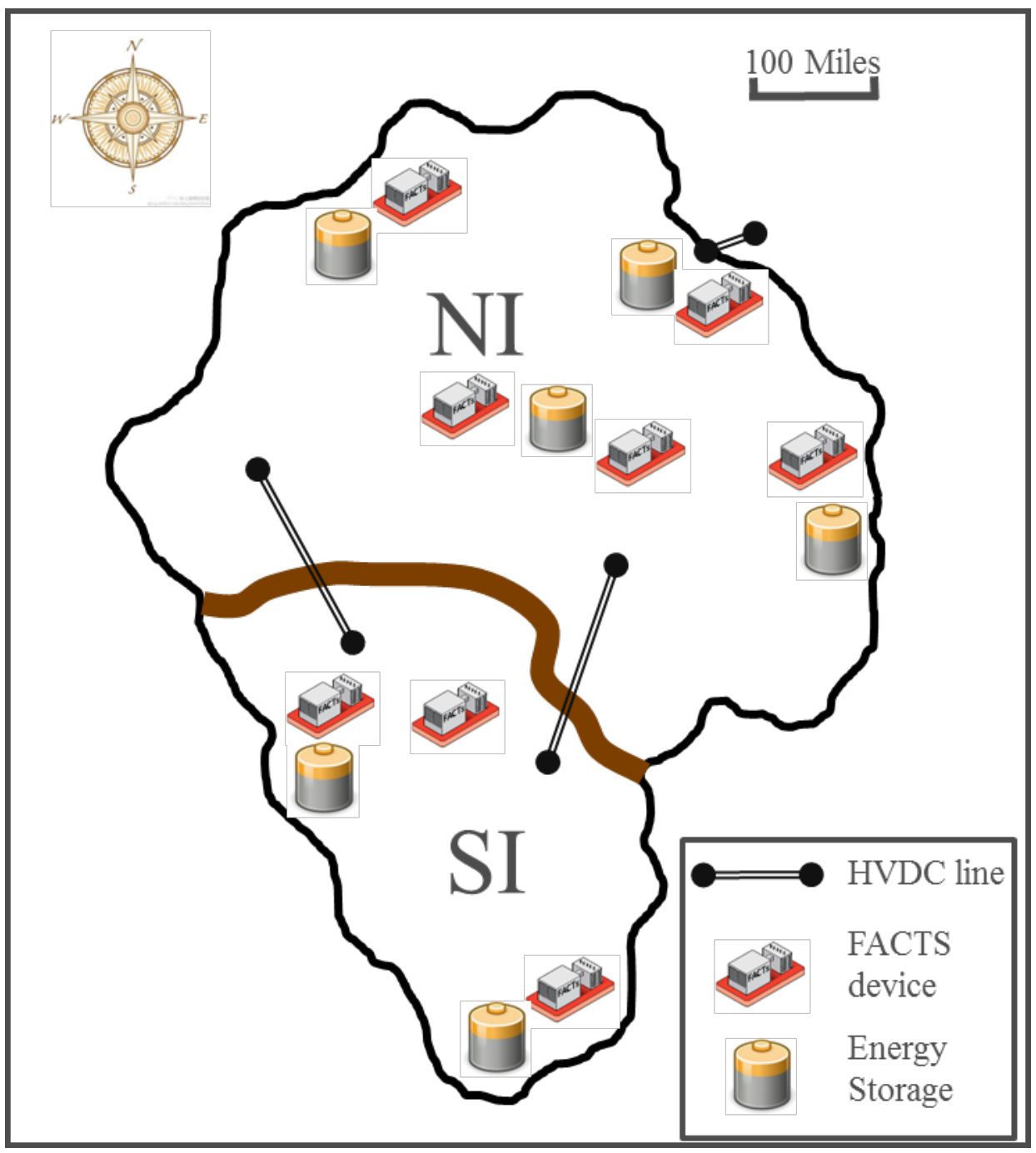

Fig. 4.6. FACTS, energy storage and HVDC line locations in the notional grid.

\subsection{INTER-AREA OSCILLATION AREAS}

Oscillations happen due to a weak connection between areas or regions. To replicate the U.S. power grid inter-area oscillation features, the inter-area oscillations will be created among three coastal regions (NWCR, NCR, and NECR) and inland region (NIR) for the North Interconnection (as shown in Fig. 4.7). For South Interconnection, the oscillation will be among SWCR, SECR, and SIR. The oscillation modes (mode frequency, damping ratio, and mode shape) in this notional power grid will be tuned to match the FNET/GridEye measurement from the U.S. power grids [29]. 


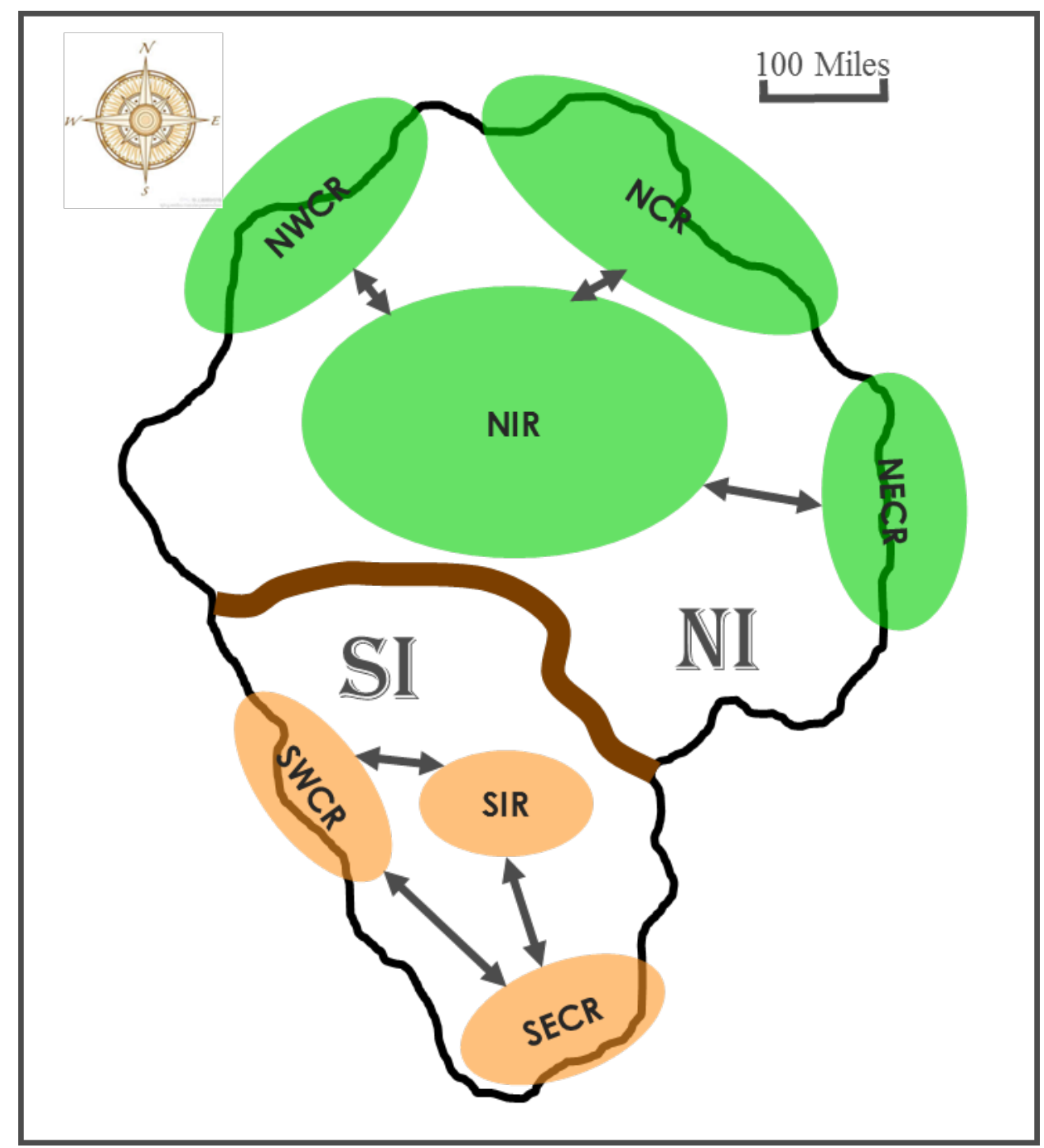

Fig. 4.7. Inter-area oscillations in the notional Atlantis grid.

\subsection{LOAD COMPOSITION}

Load modeling is very important to power system dynamics study. The industry practice of load modeling is to model the loads as constant power/admittance/current. The accuracy of this method has been proven to be acceptable for power grid transmission planning studies. However, it may not give credible simulation results for other research purposes, such as the the study of FIDVR events. Therefore, for some areas/zones in this notional system, instead of constant power/admittance/current load, detailed dynamic load models will be utilized. Below is the residential/commercial/industrial load composition conversion from [36] (as shown in Table 4.2). If a load is defined to be residential, it will consist of $64.4 \%$ small motor load, $3.7 \%$ discharge lightning load, $1.0 \%$ transfer sauration, $4.1 \%$ constant MVA, and $26.8 \%$ remaining load. This load composition can be directly realized by PSS/E complex load model as shown in Fig. 4.8 [31]. 
Table 4.2. Residual/Commercial/Industrial load composition.

\begin{tabular}{lcccccc}
\hline & $\begin{array}{c}\text { Large } \\
\text { motors } \\
\mathbf{( \% )}\end{array}$ & $\begin{array}{c}\text { Small } \\
\text { motors } \\
\mathbf{( \% )}\end{array}$ & $\begin{array}{c}\text { Discharge } \\
\text { lightning } \\
\mathbf{( \% )}\end{array}$ & $\begin{array}{c}\text { Transfer } \\
\text { saturation } \\
(\mathbf{\%})\end{array}$ & $\begin{array}{c}\text { Constant } \\
\text { MVA } \\
\mathbf{( \% )}\end{array}$ & $\begin{array}{c}\text { Remaining } \\
\text { loads } \\
\mathbf{( \% )}\end{array}$ \\
\hline Residential & 0.0 & 64.4 & 3.7 & 1.0 & 4.1 & 26.8 \\
\hline Commercial & 0.0 & 46.7 & 41.5 & 1.0 & 4.5 & 6.3 \\
\hline Industrial & 65.0 & 15.0 & 10.0 & 1.0 & 5.0 & 4.0 \\
\hline
\end{tabular}

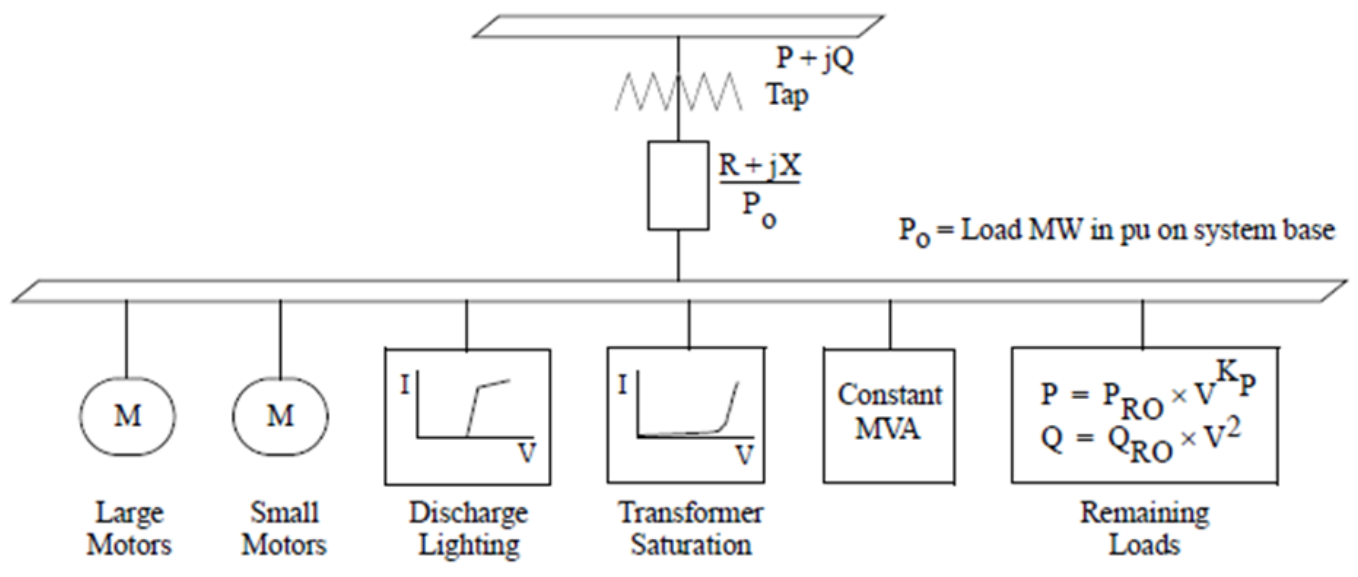

Fig. 4.8. PSS/E complex load model.

\subsection{CONTROLLABLE LOAD AMOUNT AND DISTRIBUTION}

Demand response is widely expected to play a significant role in future power grid operations. To facilitate the corresponding study, a certain percentage of loads in this notional power system will be modeled as controllable loads that can engage in the system operation and control. This controllable load modeling process does not change the power flow modeling; it only involves the dynamic simulation. In the Atlantis grid, the controllable loads will be mostly located within major load centers as one would expect. The amount of controllable load can be found in Table 3.2.

\subsection{SUMMARY OF NOTIONAL GRID FEATURES}

As discussed above, various features such as renewable generating systems, protection systems, and power electronic control device representations will be included in the proposed Atlantis power grid in order to make a competent platform for most of power system operation and control studies. These features are summarized in Fig. 4.9. Layer 2 represents the IEEE 118-bus equivalent of the large notional system (including power flow and dynamics); layers 3 through 8 represent features that go beyond current power system modeling tools. 


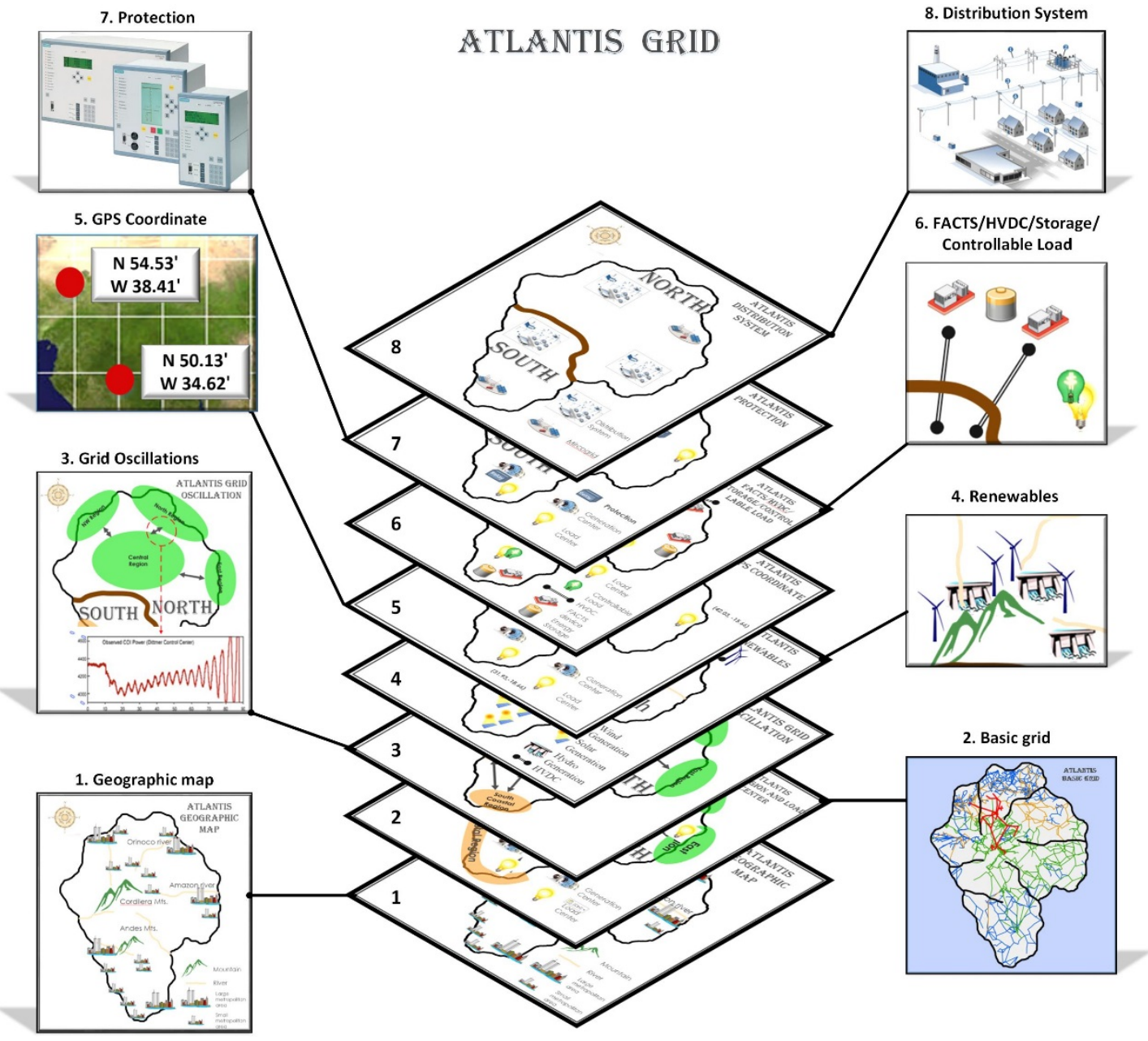

Fig. 4.9. Features of notional Atlantis power grid model in layers. 



\section{OPERATION AND MAINTENANCE REQUIREMENTS}

\subsection{DEVELOPMENT OF EXAMPLE CONTINGENCY CASES}

Power grid stability issues, e.g. frequency/angle stability, voltage stability, and small-signal stability, are among the top concerns of power grid operators. One of this notional power grid model's main applications will be studying the various power grid stability problems. To facilitate these studies, some example contingency cases will be developed based on this platform. The specific examples are yet to be defined but they may include:

- Contingency cases that lead to frequency/angle instability. Generators or tie lines will be tripped at certain key nodes to drive a certain area of the notional power grid to its frequency/angle stability limit. With a decreasing frequency/angle stability margin as will be implemented in this contingency case, advanced instability warning algorithms can be demonstrated. New control devices or methods to enhance a power grid's frequency/angle stability can also be tested.

- Contingency cases that lead to voltage instability. To create a voltage instability contingency for a load center, generators or tie lines around it will be tripped and the total load capacity within this load center will be increased incrementally. In this contingency case, the voltage instability warning algorithms and voltage stability enhancement controls can be tested.

- Contingency cases that lead to inter-area oscillations. The connection between two areas of the notional power grid will be weakened by tripping tie lines or generators to incite the inter-area oscillations. New oscillation modal analysis methods and oscillation damping controller designs can be tested as a result.

- Other contingency cases. Other contingency cases may be developed for other studies, such as studying the effects of modifying protection system philosophies.

\subsection{DEVELOPMENT OF USER TOOLS}

Though the notional grid model will be designed to meet the requirements of most of power system power flow and dynamics studies, future users may still find it useful to tailor the model to their own particular needs. For instance, though not realistic in the real world, some extreme scenarios with very severe poorly-damped inter-area oscillations may be needed for some oscillation researchers to test the robustness of their oscillation damping controls. Therefore, based on the basic simulation scenarios, they may want to make some minor changes in order to decrease the damping of certain inter-area oscillation modes. To facilitate the flexible use of this notional grid model, some scripts, tools, or guidelines will be delivered in this project to help future users make full usage of the model. While the toolkit is yet to be specified, the tools may include:

- Scripts/Tools to modify the power flow. Power flow is fundamental to any power system simulation study. The power flow modification tool will provide future users a convenient way to adjust the parameters of generators, loads, transformers, and branches.

- Scripts/Tools to change a load composition. As mentioned in the previous chapter, the prevailing constant power/admittance/current load modeling method will be employed for most of the loads in the notional grid model. For certain areas with distribution 
representation, a more detailed load modeling method will be utilized. In either way, future users will have full flexibility to change the load compositions. This tool will be especially beneficial to voltage stability studies.

- Guidelines/tools to develop a user-defined model. One of the main purposes of this notional power grid model is to test and demonstrate novel power system control methodologies. Therefore, as new control methods emerge, users have a tool to build their own control models. For example, wind and PV plants have been suggested to engage in the frequency regulation and oscillation damping [37]-[41]. As another example, measurement-based modeling and control methods have been proposed [42][43]. Hence, general guidelines or tools will be provided to help future users build these kinds of new models and test them in this notional power system.

- Automated tools to add/modify a dynamic model. Once a new dynamic model is built by the user, hundreds of them may be needed to insert into the notional power system model. As a result, an automated tool to add/modify dynamic models will be created to accelerate this process.

\subsection{POST RELEASE OPERATION AND MAINTENANCE}

Once the notional power grid has been implemented and fully tested, some maintenance will be required to provide for the widespread utilization of this notional grid. To help with this, a public website will be established and maintained in order to:

- Provide for downloading the notional power system model. The notional power grid model will be published on the website, and anyone with permission will have access to download it directly from the website.

- Provide for downloading updated versions of the model as they are developed.

- Provide for downloading the model manual. A model manual will be provided on this website to give a detailed description of this model.

- Provide guidelines, scripts, and tools for users to tailor the model. As discussed in the previous section, some scripts, tools, or guidelines will be developed to help future users modify this model to fit their particular needs. These tools will also be published on the website for the user to download.

- Provide a platform where all the users can share their user-defined models or scenarios.

- Provide an FAQ section. Some common questions will be answered in this part for future users' reference.

In the operation of this website, administration levels will be assigned to all users. These are:

- Level A - these users will have READ access to the materials on the website.

- Level B - these users will have access to download the model and manual from the webisite. 
- Level C - these users will have full access to all the materials on the website.

\subsection{POST RELEASE UPDATES}

Some of the future uses for the notional grid may not be obvious at this point. If any new uses emerge, it may be necessary to update this notional power grid model to cater to the new needs. Though future users can tailor this model on their own using the provided tools discussed earlier, the project team will publish updated versions of the model or toolkit (contingent upon appropriate funding from sponsors) if a widespread need becomes clear. Some possible updates may include:

- More scenarios. Two scenarios will be created as the first step. In the future, scenarios may be created to study higher renewable penetration levels (up to $50 \%$ or even higher), or higher penetration of FACTS devices.

- Conversion to other simulation environments. The model will be developed in the PSS/E environment as the first step, but can be converted to other simulation environments if the demand emerges.

- Modeling new control device or methodology. New control devices or methods may emerge in the future. Though tools or scripts will be provided to help the users develop their own models, the project team will publish new device models if the need emerges.

- Adding new tools to the toolkit. More tools that help the users to tailor the notional system model may be developed. 



\section{MANAGEMENT PLAN}

\subsection{ESTIMATE RELEASE TIMELINE OF PHASES OF THE PROJECTS}

The model building process will occur in three stages, namely power flow, dynamic model and model validation. The general procedure of building a particular simulation scenario is given below in Fig. 6.1. Note the validation process is iterative and starts from the first step.

\section{Power flow}

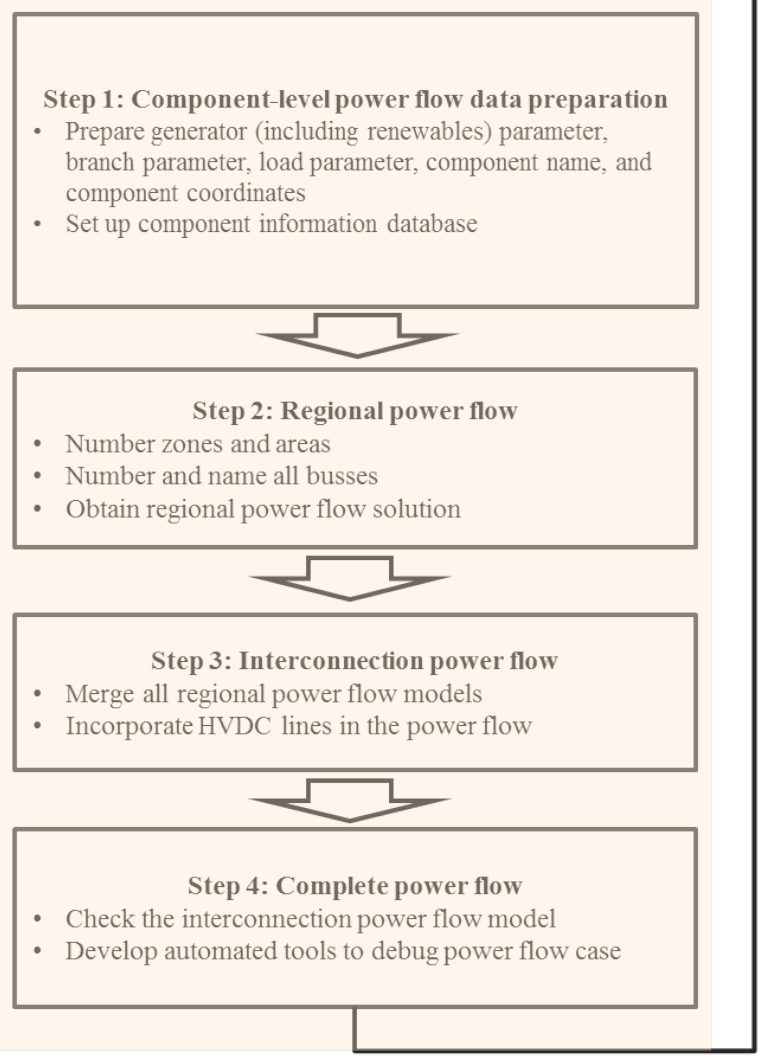

\section{Dynamic simulation}

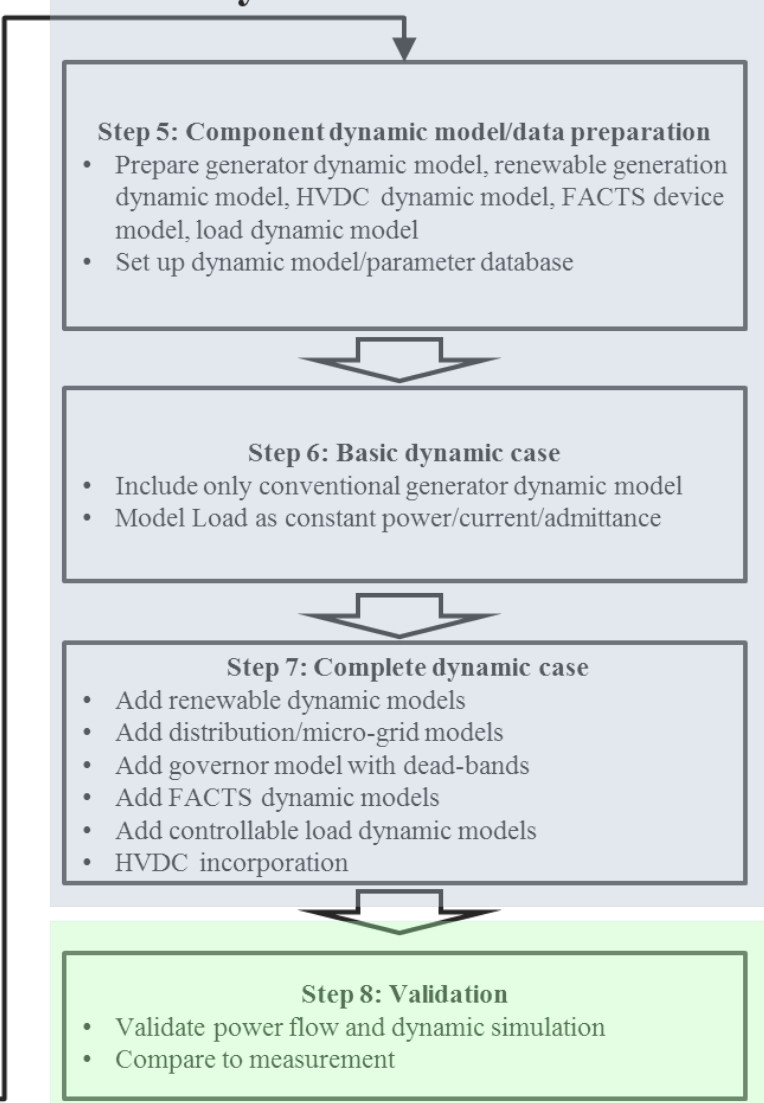

Fig. 6.1. General procedure of building a simulation scenario.

- Step 1: Component-level power flow data preparation. Typical power system component parameters will be collected and documented in this step. The project team will also look into the existing large-scale power system models, such as the EI model ranging from 16,000 to 60,000-bus, WECC, ERCOT and NPCC systems, to retrieve the most realistic parameters. During this process, all the critical energy infrastructure information, such as generator name/location/capacity will be concealed and protected.

- Step 2: Regional power flow. Based on the collected power system component parameters and typical network topology, regional power flow cases will be preliminarily established and their convergence will be tested. Furthermore, in order to create the most realistic power grid topology, some areas/zones of the existing large-scale models will be used as benchmarks or directly borrowed. Again, all the critical energy infrastructure 
information, such as bus name and location, will be completely changed and strictly protected. The naming of regions/areas/zones/buses in the notional grid model will also be completed in this step.

- Step 3: Interconnection power flow. After fully testing the regional power flow cases, they will be put together to form the interconnection power flow case. HVDC lines will be incorporated as injections in this step.

- Step 4: Complete power flow. The two interconnection power flow cases will be merged together in this step and the overall convergence will be examined. Tools to help future users modify the power flow will also be developed and documented.

- Step 5: Dynamic model/data preparation. Typical models and parameters of power system components, such as steam turbine-generator models wind generator turbine models, and others will be collected from the existing large-scale power system models at this step. It should be noted that a small percentage of component models in the existing large models are user-defined, such as in the U.S. EI MMWG model. Since these userdefined models are not common and also not convenient to convert into other simulation environments, their information will not be collected at this step.Step 6: Basic dynamic case. Based on the complete power flow case, a basic dynamic case will be established. In this step, all the loads will be modeled in the conventional way as constant power, current or admittance. And all the FACTS/controllable load/storage devices will be modeled as constant power sources in this step.

- Step 7: Complete dynamic case. After a full test of the basic dynamic case, the dynamic models for renewable generating sources, FACTS devices, controllable loads, HVDC lines, and governors (with dead-bands) will be implemented in this step. The model convergence will be monitored and tested after adding any new models.

- Step 8: Model validation. Several validation methods will be applied to validate this model and changes will be made based on the validation results. Again, existing large-scale power system models as well as field measurements will be used in the validation process.

The project team's past large-scale power system model development experience, especially the effort of building the 2030 U.S. EI dynamic model, will be leveraged to build this notional grid model. A research task schedule and the corresponding estimated labor requirements (in FTEs) is presented in Table 6.1. 
Table 6.1. Research task schedule and labor estimate.

\begin{tabular}{|c|c|c|c|c|c|}
\hline & & $\begin{array}{c}\text { Total } \\
\text { FTE } \\
\text { Required }\end{array}$ & Year 1 & Year 2 & Year 3 \\
\hline & & (10.0) & 0102030 & 010203 & 1020304 \\
\hline Milestone 1 & $\begin{array}{l}\text { Base case power } \\
\text { flow Model }\end{array}$ & 1.6 & $\mathrm{X} \mathrm{X}$ & & \\
\hline $\begin{array}{l}\text { Basic load flow and } \\
\text { dynamic model }\end{array}$ & $\begin{array}{l}\text { Base case } \\
\text { dynamic model }\end{array}$ & 1.4 & $\mathrm{XX}$ & & \\
\hline & High renewable case & 0.5 & $\mathrm{X}$ & & \\
\hline $\begin{array}{c}\text { Milestone 2 } \\
\text { High renewable case, add } \\
\text { GPS coordinates }\end{array}$ & Add GPS coordinates & 0.8 & & & \\
\hline Milestone 3 & $\begin{array}{l}\text { Add governors } \\
\text { dead-band }\end{array}$ & 0.3 & & $\mathrm{X}$ & \\
\hline $\begin{array}{l}\text { Add governors with dead- } \\
\text { band, HVDCs, FACTSs, }\end{array}$ & $\begin{array}{l}\text { Add HVDC and } \\
\text { FACTS devices }\end{array}$ & 0.5 & & $\mathrm{X}$ & \\
\hline $\begin{array}{c}\text { controllable loads, } \\
\text { storages }\end{array}$ & $\begin{array}{l}\text { Add storage device } \\
\text { models }\end{array}$ & 0.5 & & $\mathrm{X}$ & \\
\hline & $\begin{array}{l}\text { Add controllable } \\
\text { load models }\end{array}$ & 0.5 & & $\mathrm{X}$ & \\
\hline Milestone 4 & $\begin{array}{l}\text { Add protection } \\
\text { models }\end{array}$ & 0.8 & & $\mathrm{X}$ & \\
\hline $\begin{array}{c}\text { Add protections, sample } \\
\text { distribution } \\
\text { systems/micro-grid } \\
\text { models }\end{array}$ & $\begin{array}{l}\text { Add distribution } \\
\text { systems/micro-grids }\end{array}$ & 0.5 & & $\mathrm{X}$ & \\
\hline Milestone 5 & $\begin{array}{l}\text { Contingency cases } \\
\text { development }\end{array}$ & 0.3 & & & \\
\hline $\begin{array}{c}\text { Continuing operations and } \\
\text { maintenance }\end{array}$ & $\begin{array}{l}\text { User toolkits } \\
\text { development }\end{array}$ & 0.5 & & & \\
\hline & $\begin{array}{l}\text { Website development } \\
\text { and maintenance }\end{array}$ & 0.5 & & & \\
\hline Milestone 6 & $\begin{array}{l}\text { Real-time operation } \\
\text { implementation }\end{array}$ & 0.8 & & & $\mathrm{X}$ \\
\hline Real time operation $^{11}$ & $\begin{array}{l}\text { Real-time } \\
\text { visualization/control } \\
\text { test and demo }\end{array}$ & 0.5 & & & $\mathrm{X}$ \\
\hline
\end{tabular}

\subsection{DEFINE DOCUMENTATION REQUIRED FOR EACH VERSION}

As mentioned in Chapter 5, a detailed model manual will be published along the model to help future users better understand and more fully utilize this notional power grid model. This manual will include the detailed information of the notional power grid model, the toolkits developed to help users

11 Further details are in Appendix A. 
tailor this model, and example contingency cases. The main content of this documentation is listed in Table 6.2.

Table 6.2. Manual for each version.

\begin{tabular}{|c|c|}
\hline Documentation Type & Documentation Content \\
\hline \multirow{6}{*}{$\begin{array}{l}\text { Power flow information } \\
\text { database }\end{array}$} & Generator parameters \\
\hline & Transformer parameters \\
\hline & Line parameters \\
\hline & Load parameters \\
\hline & Bus names/numbers/coordinates \\
\hline & Zones/area numbers \\
\hline \multirow{7}{*}{ Dynamic data database } & Generator dynamic data \\
\hline & Load model dynamic data \\
\hline & FACTS dynamic data \\
\hline & HVDC dynamic data \\
\hline & Storage dynamic data \\
\hline & Protection device data \\
\hline & User-defined model \\
\hline \multirow{4}{*}{ Toolkits help files } & Help file for tool to modify power flows \\
\hline & $\begin{array}{l}\text { Help file for tool to change load } \\
\text { compositions }\end{array}$ \\
\hline & $\begin{array}{l}\text { Help file for tool to develop user-defined } \\
\text { models }\end{array}$ \\
\hline & $\begin{array}{l}\text { Help file for tool to add/modify dynamic } \\
\text { models }\end{array}$ \\
\hline \multirow{4}{*}{$\begin{array}{l}\text { Description of example } \\
\text { contingency cases }\end{array}$} & Frequency/angle stability contingency case \\
\hline & Voltage stability contingency case \\
\hline & Small-signal stability contingency case \\
\hline & Other contingency cases \\
\hline
\end{tabular}




\section{CONCLUSIONS}

A plan for building a realistic but open source large-scale power system model is introduced in this scoping study. This virtual power grid platform will be mapped to the imaginary Atlantis continent and its design delivers a means to apply the tool to many and varied large-scale power system stability and control studies. Once completed, this model will provide both the research community and industry with a standard platform to evaluate the performance of the electric grid in light of new generation technologies and novel control algorithms in an environment realistic to the real grid. This platform will significantly accelerate the pace of technology development and, more importantly, the pace of technology adoption. 



\section{REFERENCES}

[1] J.C. Smith, M.R. Milligan, E.A. DeMeo, B. Parsons, "Utility Wind Integration and Operating Impact State of the Art," Power Systems, IEEE Transactions on, vol. 22, no.3, pp.900-908, Aug. 2007.

[2] E. Denny, M. O'Malley, "Wind Generation, Power System Operation, and Emissions Reduction," Power Systems, IEEE Transactions on, vol. 21, no.1, pp.341-347, Feb. 2006.

[3] S. Eftekharnejad, V. Vittal, G.T. Heydt, B. Keel, J. Loehr, "Impact of Increased Penetration of Photovoltaic Generation on Power Systems," Power Systems, IEEE Transactions on, vol.28, no.2, pp.893-901, May 2013.

[4] J. De La Ree, V. Centeno, J.S. Thorp, A.G. Phadke, "Synchronized Phasor Measurement Applications in Power Systems," Smart Grid, IEEE Transactions on, vol.1, no.1, pp.20-27, June 2010.

[5] V. Terzija, G. Valverde, Deyu Cai; P. Regulski, V. Madani, J. Fitch, S. Skok, M.M. Begovic, A. Phadke, "Wide-Area Monitoring, Protection, and Control of Future Electric Power Networks," Proceedings of the IEEE, vol.99, no.1, pp.80-93, Jan. 2011.

[6] M. Klein, G.J. Rogers, P. Kundur, "A Fundamental Study of Inter-area Oscillations in Power Systems," Power Systems, IEEE Transactions on, vol.6, no.3, pp.914-921, Aug. 1991.

[7] P. Kundur, M. Klein, G.J. Rogers, M.S. Zywno, "Application of Power System Stabilizers for Enhancement of Overall System Stability," Power Systems, IEEE Transactions on, vol.4, no.2, pp.614-626, May 1989.

[8] X. Yang, A. Feliachi, "Stabilization of Inter-area Oscillation Modes through Excitation Systems," Power Systems, IEEE Transactions on, vol.9, no.1, pp.494-502, Feb. 1994.

[9] M. Zarghami, M.L. Crow, J. Sarangapani, Yilu Liu; S. Atcitty, "A Novel Approach to Interarea Oscillation Damping by Unified Power Flow Controllers Utilizing Ultracapacitors," Power Systems, IEEE Transactions on, vol.25, no.1, pp.404-412, Feb. 2010.

[10] J. Ni; C. Shen; F. Liu, "Estimating the Electromechanical Oscillation Characteristics of Power System based on Measured Ambient Data Utilizing Stochastic Subspace Method," Power and Energy Society General Meeting, 2011 IEEE, vol., no., pp.1-7, 24-29 July 2011.

[11] Deparment of Homeland Security, "National Power Grid Simulation Capability: Needs and Issues," http://web.anl.gov/eesa/pdfs/brochures/PowerGridBrochure.pdf , 2008.

[12] ERAG, "Multiregional Modeling Working Group (MMWG) Procedural Manual," https://rfirst.org/reliability/easterninterconnectionreliabilityassessmentgroup/mmwg/Documents /MMWG\%20Procedure\%20Manual\%20V11.pdf, 2014.

[13] N. Hutcheon, J.W. Bialek, "Updated and validated power flow model of the main continental European transmission network," PowerTech (POWERTECH), 2013 IEEE Grenoble, vol., no., pp.1-5, 16-20 June 2013.

[14] Y. Liu, "A US-wide Power Systems Frequency Monitoring Network," Power and Energy Society Transmission and Distribution Conference, vol., no., pp. 159-166, 2006.

[15] Z. Zhong, C. Xu, B. J. Billian, L. Zhang, S. S. Tsai, R. W. Conners, V. A. Centeno, A. G. Phadke, Y. Liu, "Power system Frequency Monitoring Network (FNET) Implementation," Power Systems, IEEE Transactions on, vol. 20, no. 4, pp. 1914-1921, Nov. 2005.

[16] Y. Zhang, P. N. Markham, T. Xia, L. Chen, Y. Ye, Z. Wu, Z. Yuan, L. Wang, J. Bank, J. Burgett, R. W. Conners, Y. Liu, "Wide-area Frequency Monitoring Network (FNET) Architecture and Applications," Smart Grid, IEEE Transactions on, vol. 1, no. 2, pp. 159-167, Sept. 2010.

[17] Z. Lin, Y. Liu, Y. Jia, Y. Zhang, T. Xia, Y. Liu, F. Wen, "Dynamic performance test of singlephase phasor measurement units," Power and Energy Society General Meeting, 2011 IEEE , vol., no., pp.1,7, 24-29 July 2011. 
[18] L. Zhan, Y. Liu, J. Culliss, J. Zhao, Y. Liu, "Dynamic single-phase synchronized phase and frequency estimation at the distribution level," Smart Grid, IEEE Transactions on, vol. 6, no. 4, pp.2013-2022, July 2015.

[19] Y. Liu, L. Zhan, et. al, "Wide-Area Measurement System Development at the Distribution Level: an FNET/GridEye Example," Power Delivery, IEEE Transactions on, vol. PP, no.99, pp.1-1,2015.

[20] N. Flourentzou, V.G. Agelidis, G.D. Demetriades, "VSC-Based HVDC Power Transmission Systems: An Overview," Power Electronics, IEEE Transactions on, vol. 24, no. 3, pp.592-602, March 2009.

[21] M.P. Bahrman, B.K. Johnson, "The ABCs of HVDC Transmission Technologies," Power and Energy Magazine, IEEE, vol.5, no.2, pp.32-44, March-April 2007.

[22] L. Gyugyi, C.D. Schauder, S.L. Williams, T.R. Rietman, D.R. Torgerson, A. Edris, "The Unified Power Flow Controller: a New Approach to Power Transmission Control," Power Delivery, IEEE Transactions on, vol.10, no.2, pp.1085-1097, Apr. 1995.

[23] R.T. Byerly, D.T. Poznaniak, E.R. Taylor, "Static Reactive Compensation for Power Transmission Systems," Power Apparatus and Systems, IEEE Transactions on, vol.PAS-101, no.10, pp.3997-4005, Oct. 1982.

[24] P.F. Ribeiro, B.K. Johnson, M.L. Crow, A. Arsoy, Y. Liu, "Energy Storage Systems for Advanced Power Applications," Proceedings of the IEEE, vol.89, no.12, pp.1744-1756, Dec. 2001.

[25] P. Kundur, Power System Stability and Control. New York: McGraw-Hill, Inc. 1994.

[26] F.J. Meyer, K.Y. Lee, "Improved Dynamic Load Model for Power System Stability Studies," Power Engineering Review, IEEE, vol.PER-2, no.9, pp.49-50, Sept. 1982.

[27] NERC, "A Technical Reference Paper Fault-Induced Delayed Voltage Recovery", http://www.nerc.com/docs/pc/tis/FIDVR_Tech_Ref\%20V1-2_PC_Approved.pdf, 2009

[28] D. Sullivan, R. Pape, J. Birsa, M. Riggle, M. Takeda, H. Teramoto, Y. Kono, K. Temma, S. Yasuda, K. Wofford, P. Attaway, J. Lawson, "Managing Fault-Induced Delayed Voltage Recovery in Metro Atlanta with the Barrow County SVC," Power Systems Conference and Exposition, 2009 IEEE PES, vol., no., pp.1-6, 15-18 March 2009.

[29] Z. Yuan; T. Xia; Y. Zhang; L Chen; P.N. Markham, R.M. Gardner, Y. Liu, "Inter-area Oscillation Analysis using Wide Area Voltage Angle Measurements from FNET," Power and Energy Society General Meeting, 2010 IEEE, vol., no., pp.1-7, 25-29 July 2010.

[30] University of Queensland, "Development of a Comprehensive Power System Simulation Laboratory (PSS-L)", 2010.

[31] PSS ${ }^{\circ}$ E Version 32. Manual.

[32] http://www.eia.gov/electricity/

[33] http://en.wikipedia.org/wiki/Atlantis

[34] J.P. Barton, D.G. Infield, "Energy Storage and Its Use with Intermittent Renewable Energy," Energy Conversion, IEEE Transactions on, vol.19, no.2, pp.441-448, June 2004.

[35] R.K. Varma, S. Auddy, Y. Semsedini, "Mitigation of Subsynchronous Resonance in a SeriesCompensated Wind Farm Using FACTS Controllers," Power Delivery, IEEE Transactions on, vol.23, no.3, pp.1645-1654, July 2008.

[36] J.A. Diaz de Leon, B. Kehrli, "The Modeling Requirements for Short-Term Voltage Stability Studies," Power Systems Conference and Exposition, 2006 IEEE PES, vol., no., pp.582-588, Oct. 292006.

[37] Y. Liu, Jose Gracia, et al, Oak Ridge National Laboratory, "Wind/PV Generation for Frequency Regulation and Oscillation Damping in the Eastern Interconnection (EI)", http://info.ornl.gov/sites/publications/Files/Pub47594.pdf, 2013.

[38] Y. Liu, L. Zhu, L. Zhan, J. R. Gracia, T. J. King, Y. Liu, "Active Power Control of Solar PV Generation for Large Interconnection Frequency Regulation and Oscillation Damping," International Journal of Energy Research, 2015. 
[39] Y. Liu, J. R. Gracia, J. K. Thomas, Y. Liu, "Frequency Regulation and Oscillation Damping Contributions of Variable-speed Wind Generators in the U.S. Eastern Interconnection (EI)," Sustainable Energy, IEEE Transaction on, vol. 6, no. 3, July 2015.

[40] Y. Liu, Y. Liu, J.R. Gracia, T.J. King, "Oscillation damping contributions of variable-speed wind generators in the Eastern Interconnection (EI)," PES General Meeting | Conference \& Exposition, 2014 IEEE, vol., no., pp.1,5, 27-31 July 2014.

[41] Y. Liu, Y. Liu, J. R. Gracia, T. J. King, "Variable-speed wind generation control for frequency regulation in the Eastern Interconnection (EI)," T\&D Conference and Exposition, 2014 IEEE PES , vol., no., pp.1,5, 14-17 April 2014.

[42] Y. Liu, K. Sun, Y. Liu, “A Measurement-based Power System Model for Dynamic Response Estimation and Instability Warning”, Electric Power Systems Research, vol. 124, pp.1-9, July 2015.

[43] H. Liu, L. Zhu, Z. Pan, F. Bai, Y. Liu, Y. Liu, M. Patel, E. Farantatos, N. Bhatt, "ARMAXbased Transfer Function Model Identification Using Wide-area Measurement for Adaptive and Coordinated Damping Control," Smart Grid, IEEE Transaction on, vol. PP, no.99, pp.1-1,2015. 
APPENDIX. A. NOTIONAL POWER GRID CASE STUDY 



\section{APPENDIX A NOTIONAL POWER GRID CASE STUDY}

The general procedure of building a realistic but open-source large-scale power system model was described in the previous chapters. To validate the effectiveness and efficiency of the proposed methodology, an example system model will be built in this appendix. Please note that this example case is not intended to have all the features discussed above, such as renewables or FACTS, but to showcase how the basic model (Milestone 1 in Table 6.1) will be built.

\section{A.1 POWER FLOW PART}

As described in Fig. 6.1, building an example system model starts with the power flow. In this section, how the power flow case is constructed will be demonstrated. Realistic parameters are extracted from a real large-scale power grid model (only power flow) commercialized by PowerWorld/Energy Visual. The steps to create the example power flow case mainly include:

- Convert the PowerWorld power flow model to PSS/E. As discussed in Chapter 2, the virtual power system model is intended to be in the PSS/E format. Therefore the PowerWorld power flow model has to be converted to PSS/E as the first step. Please note that some minor changes to the model will be necessary due to some software compatibility issues.

- Extract realistic parameters, topologies, and small pieces. In this step, python scripts were written to cut small pieces out of the large power flow model. A part of such scripts is shown in Fig. A.1.

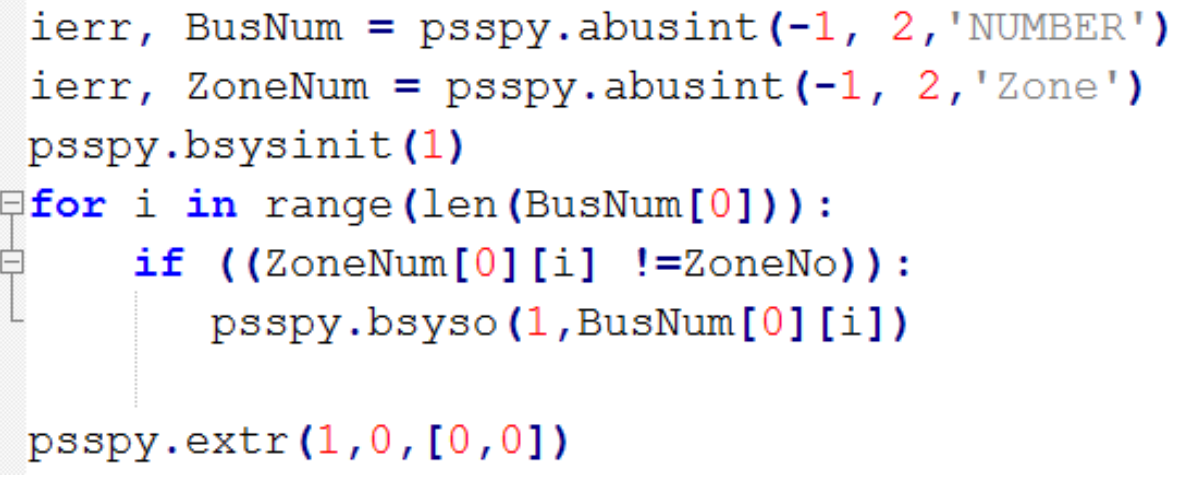

Fig. A.1. Python scripts to cut certain zone out of the original model (part).

- Build regional power flow cases. Realistic parameters, topologies, and small pieces obtained from the last step were utilized to build the regional power flow cases. The bus number of each regional power flow case may vary from several hundred to one or two thousands. Slack buses for each regional power flow case were also selected in this step and convergences of these regional power flow cases will be guaranteed. As shown in Fig. A.2, the power flow calculation will reach tolerance in a few iterations with small mismatches. 
Fig. A.2. Convergence of the regional power flow cases.

- Check islands. Some islands may be created in the previous steps. Therefore python scripts were written in this step (Fig. A.3) to check if there is any island existing in the regional power flow cases.

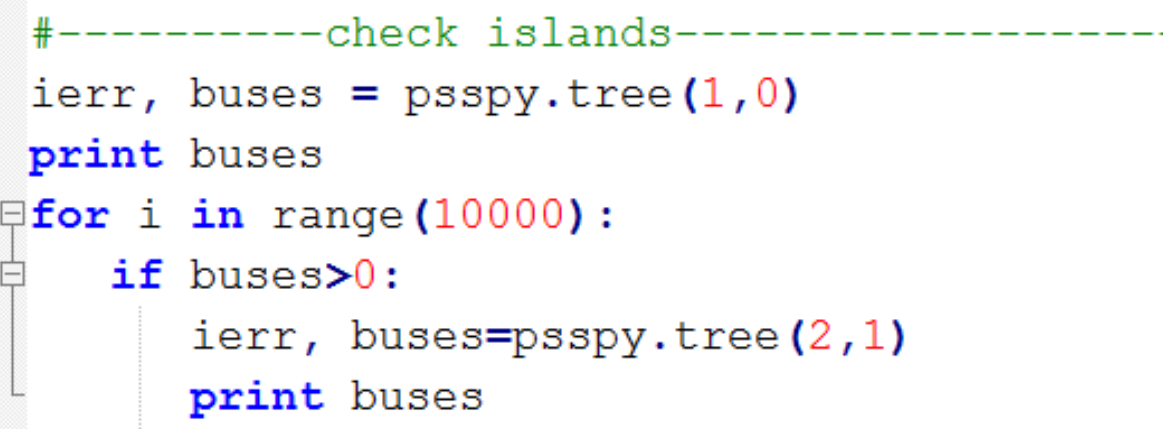

Fig. A.3. Python scripts to check islands (part).

- Read all the regional power flow cases into one sav file. After collecting enough regional power flow cases and achieving their convergences, all the regional cases were read into one sav file for further processing in this step. Since PSS/E doesn't provide such a function, python scripts were written to achieve this. Part of such scripts were given below in Fig. A.4.

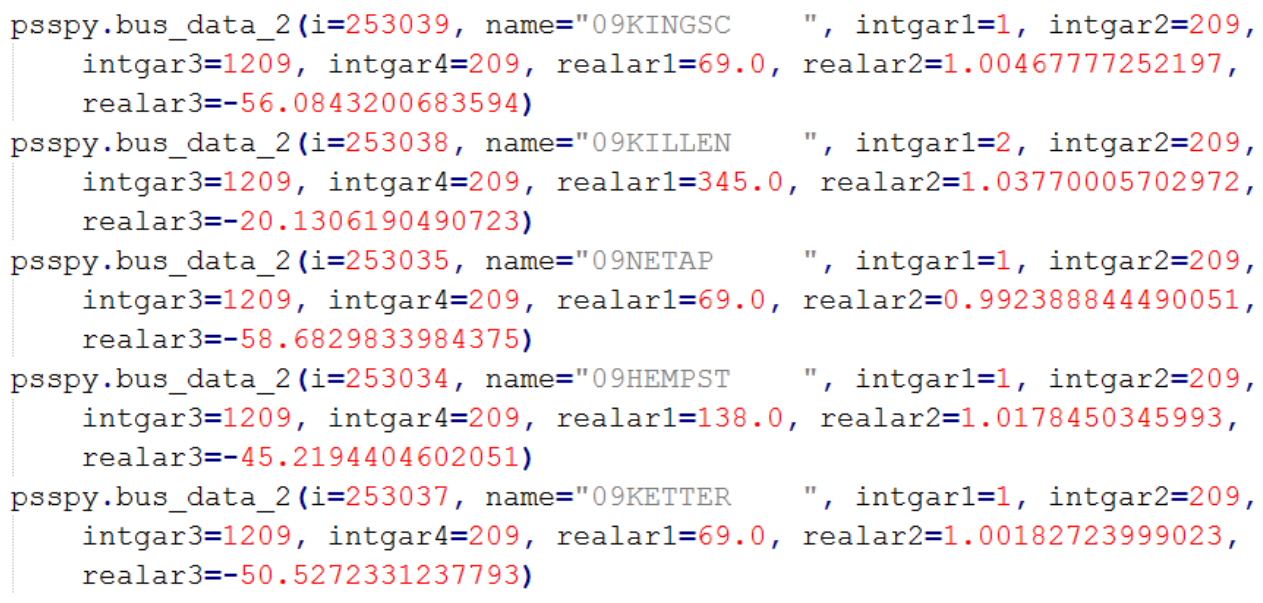

Fig. A.4. Python scripts to real the regional power flows into one file (part).

- Connect the regions using tie lines. Although the regional power flow cases were read into one sav file in last step, they haven't been connected electronically. In this step, all the regions will be connected by tie lines between each other. Voltage level, tie line power flow and tie line location are the main considerations in this process. Another 
thing worth mentioning is that, to make sure the power flow case converges, some artificial loads were used to achieve the generation-load balance.

- Draw one-line diagram of the example system and create GPS coordinates for each bus in the system. To better visualize the example system, a power system geographical information toolbox (PSGIT) was developed. Using this toolbox, a one-line diagram of this example system can be drawn automatically, as shown in Fig. A.5. GPS coordinates can also be automatically assigned to each bus based on a sophisticated geometric algorithm without changing the relative distances between buses and a geographic map can be draw as a result. Further details of this toolbox can be found in Appendix B.

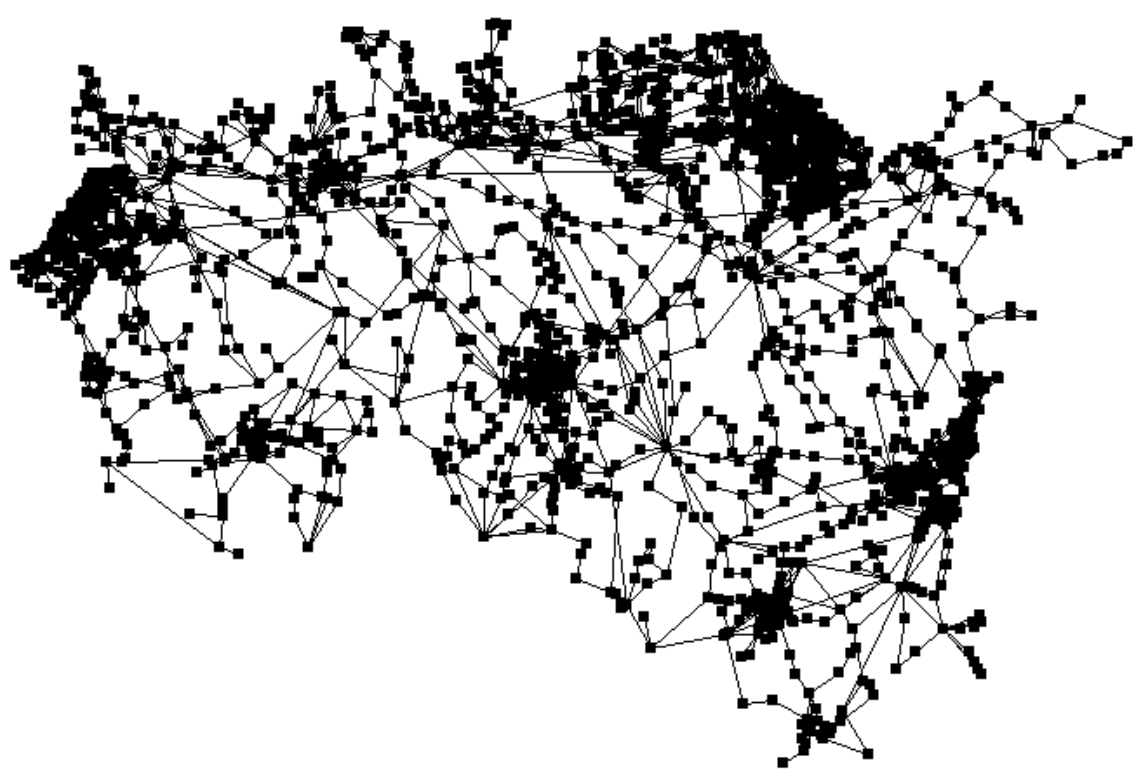

Fig. A.5. Diagram of the example system.

\section{A.2 DYNAMIC MODEL PART}

The dynamic model part of the example system consists of generator, exciter, and governor dynamic models. Depending on fuel type, the generator can be modeled by either a round rotor synchronous machine or a salient pole machine. The excitation system is represented by a generic model which features high-gain and fast-reaction. Hydro, gas, and steam turbine governor models are employed to model various types of plants that operate with different energy sources. Typical parameters are assumed for the dynamic data set. The steps to create the dynamic model part of the example system include:

- Power flow case screening process. Even the power flow case was solved, a screening process was still needed to sort out and correct erroneous static data that could cause divergence in dynamic simulations.

- Identify generator, exciter, and governor dynamic model type. A separate generator list will be prepared beforehand to identify hydro and gas units, so dynamic model types will be selected accordingly for different generator types. 
- Automatically populate generator, exciter, and governor dynamic parameters. Once the dynamic model type is fixed, a script was written to populate the parameters of dynamic models. Please note that generic parameters were used in this step.

- Conduct a flat run without any disturbance. After all the dynamic models were created, a 60 -second flat run was conducted in this step to check any possible erroneous parameters. This process is usually referred to as initialization. If the initialization fails, the initial condition suspects reported by PSS/E will indicate the machines that possibly have incorrect settings. After erroneous settings are eliminated, a bounded flat run can be reached, as shown in Fig. A.6.

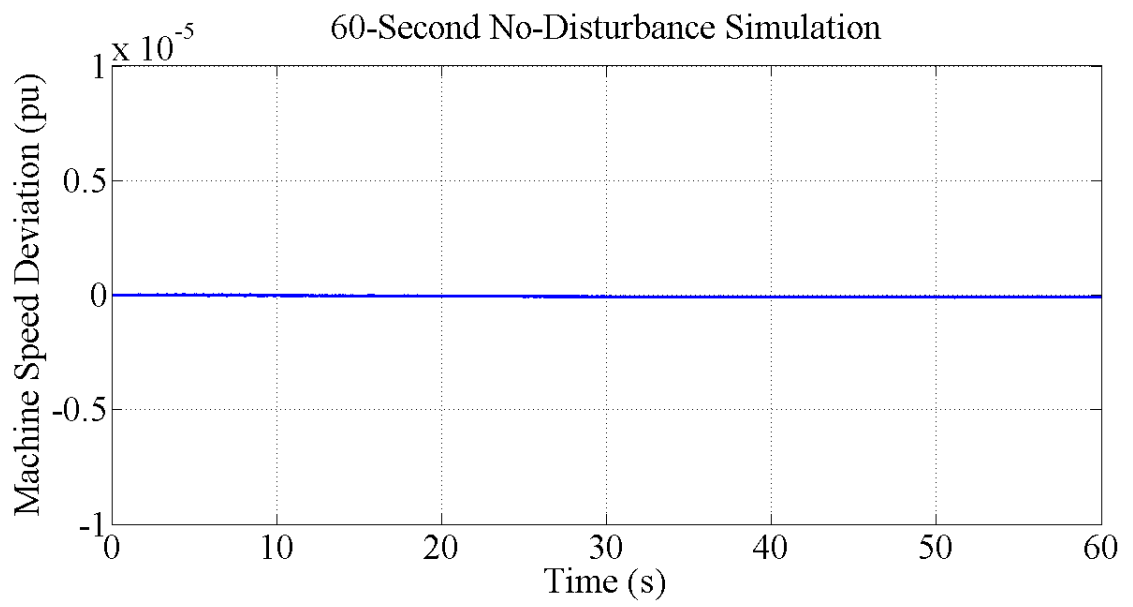

Fig. A.6. Flat run of the example power system.

- Simulate disturbances in the example system. As the last step, various disturbances, including generation trip, bus fault, and line fault, were applied across the system so as to examine the robustness of the dynamic data set (as shown in Fig. A.7). Machines that have small transient stability margin or low oscillation damping ratio requires close attention and further adjustment.

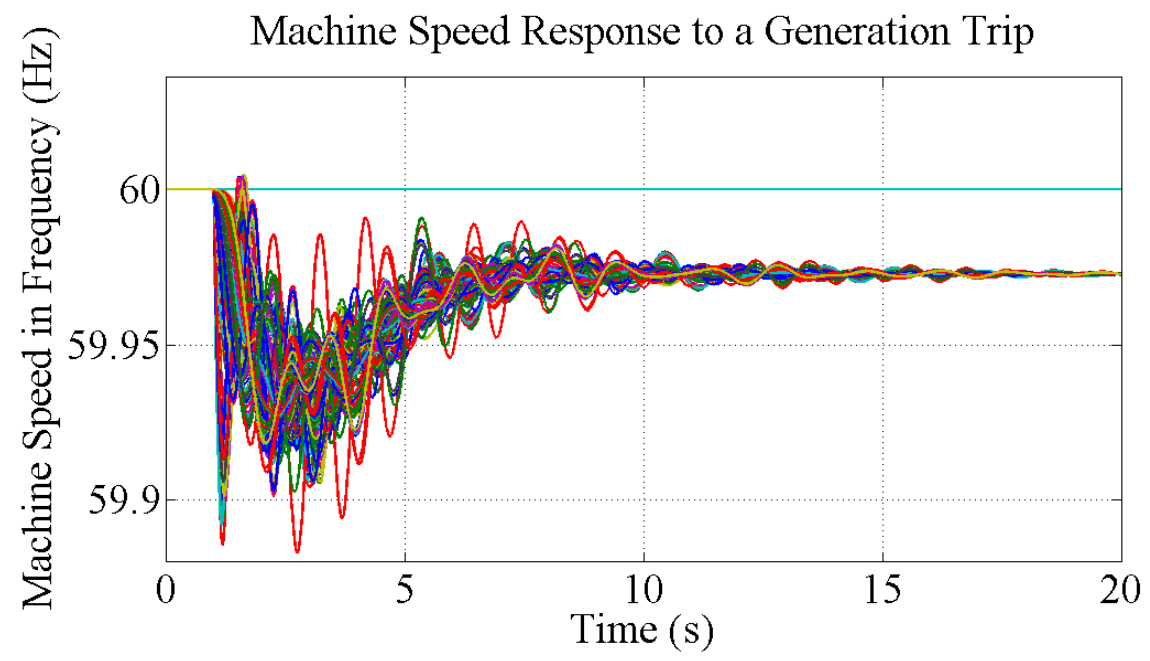

Fig. A.7. A generation trip disturbance of the example system. 
APPENDIX. B. FEASIBILITY STUDY FOR A REAL TIME NOTIONAL GRID 



\section{APPENDIX B FEASIBILITY STUDY FOR A REAL TIME NOTIONAL GRID}

\section{B.1 BENEFITS OF REAL TIME CONTINOUS OPERATIONS VS OFF-LINE SIMULATION}

Real time continuous operations will be beneficial to power system dynamics study in various ways. A comparison between continuous operation and off-line simulation is given below in Table B.1.

Table B.1. Benefit comparison between continuous and off-line operation.

\begin{tabular}{|c|c|c|}
\hline & Off-line dynamic model & Real time continuous operation \\
\hline Benefits & $\begin{array}{l}\text { - } \begin{array}{l}\text { Different simulation steps for different } \\
\text { simulation purposes }\end{array} \\
\text { - } \quad \text { Has potential to be faster than real-time } \\
\text { - } \quad \text { N-1 contingency analysis }\end{array}$ & $\begin{array}{ll}\text { - } & \text { Introduces arbitrary } \\
\text { disturbances at any time } \\
\text { - } & \text { Wide area/real-time control } \\
\text { demos } \\
\text { - } & \text { Provides data for real-time } \\
\text { visualization tool } \\
\text { - } & \text { Pauses if needed }\end{array}$ \\
\hline Drawbacks & $\begin{array}{ll}\text { - } & \text { Only pre-scheduled disturbances } \\
\text { - } & \text { Fixed starting point }\end{array}$ & - $\quad$ Higher requirements for solver \\
\hline
\end{tabular}

\section{B.2 CHALLENGES FOR REAL TIME CONTINOUS OPERATION}

Real time continuous operation is different from off-line simulations. The main challenges for continuous operation may include:

- Simulation Speed. The first challenge for continuous operation will be simulation speed. Taking the 16,000-bus EI system as an example, it usually takes five times more than the simulation time to run on a desktop. Therefore, in order to make the notional grid run in real time, the simulation speed should be fast enough.

- Time scaling techniques. Even if the simulation speed is fast enough, time scaling techniques are needed to make sure the simulation run exactly in real-time. For the wellknown real time simulators, GPS timing is introduced to the simulation process as a benchmark and each time step will be scaled to the GPS timing in order to be real-time. Equivalent time scaling techniques will be needed for real-time continuous operation.

- Solver challenges. Most commercial software are not specially designed for continuous operation, which means the solver employed may not be accurate for long-term calculation. For instance, PSS/E utilizes an improved Euler method to calculate transients over a period of few cycles to several seconds following disturbances. During this time frame, the important effects are inertial motions of turbine generators, excitation systems, loads, static Var sources, DC converters, and to a lesser extent, turbine-governors. The time step is typically 0.00833 seconds $(1 / 2$ cycles) for $60-\mathrm{Hz}$ system. For the improved Euler method, the calculation error accumulates over each time step so that the simulation cannot run for more than 20 seconds. Though another implicit trapezoidal method for extended-term simulation is provided, its time step should be limited to 0.15 to 0.2 
seconds, which means the fast process will be lost. Therefore, appropriate solvers need to be developed for continuous operation. 
APPENDIX. C. POWER SYSTEM GEOGRAPHIC TOOLBOX (PSGT) 



\section{APPENDIX C. POWER SYSTEM GEOGRAPHIC TOOLBOX (PSGT)}

\section{C.1 INTRODUCTION}

Geographic interface was not a common part of the power system analysis tools. As the rapid development of geographic information technology, geographic interface has become a critical auxiliary function of these software. In order to locate substations and transmission lines on the map, some computer-aided design software used in power system analysis add new features in order to visualize the model data and simulation results. Taking PowerWorld as an example, it has developed a geographic interface to depict the power flow calculation results. Matlab also provides a Mapping Toolbox for users to develop more advanced geographic information systems (GIS).

However, the existing tools do not allow much flexibility in creating user-defined geographic information display systems. For instance, PowerWorld can only take a built-in North America or world map and doesn't provide any function to edit (such as move and rotate) those maps. So a power system geographic toolbox (PSGT) is developed to allows us to:

- Exchange data with popular power system analysis tools. In this project, an interface to exchange data with the PSS/E raw data file was developed.

- Manipulate the topological and geographic information of a power system, such as movement and rotation of certain parts of the system. It should be noted that the distance before and after geometric transformation should be identical. Therefore, an advanced algorithm is needed to move and rotate buses or substations on the Earth's spherical surface other than using PowerWorld or Matlab Mapping Toolbox. Furthermore, more geographic data sources such as Google Earth can be imported. And more importantly, all those functions should be achieved by a few clicks instead of tedious input works.

- Develop the auxiliary functions. Other auxiliary functions may include: layer display by zone, area, voltage-level, etc., and distance calculation.

\section{C.2 TOOLBOX ARCHITECTURE}

This graphic toolbox mainly consists of two parts: text interface for PSS/E raw data (TIRD) and graphical interface for the power system (GIPS). The essential components of each part are shown in Fig. C.1. 


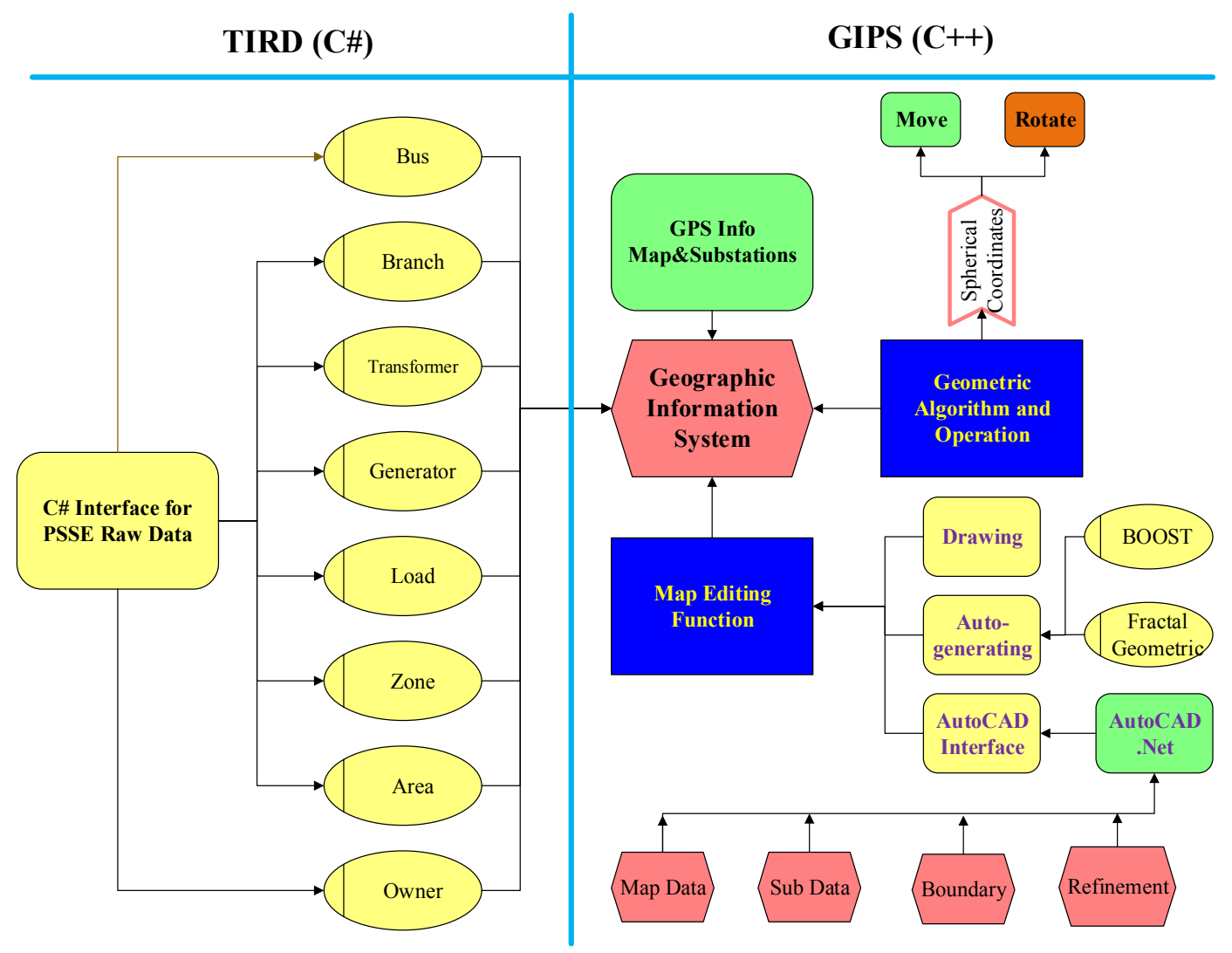

Fig. C.1. Toolbox architecture.

\section{C.3 TEXT INTERPRETER FOR RAW FILE}

As illustrated in Fig. C.1, the PSS/E raw data file can be interpreted by the C\#-based interface developed in Microsoft Visual Studio (MFC) 2013. By decomposing buses, branches, transformers, generators, loads, zones, and areas in a raw data file, all the basic information of a power system model can be imported into this toolbox. One snapshot of this interface is shown below in Fig. C.2. 


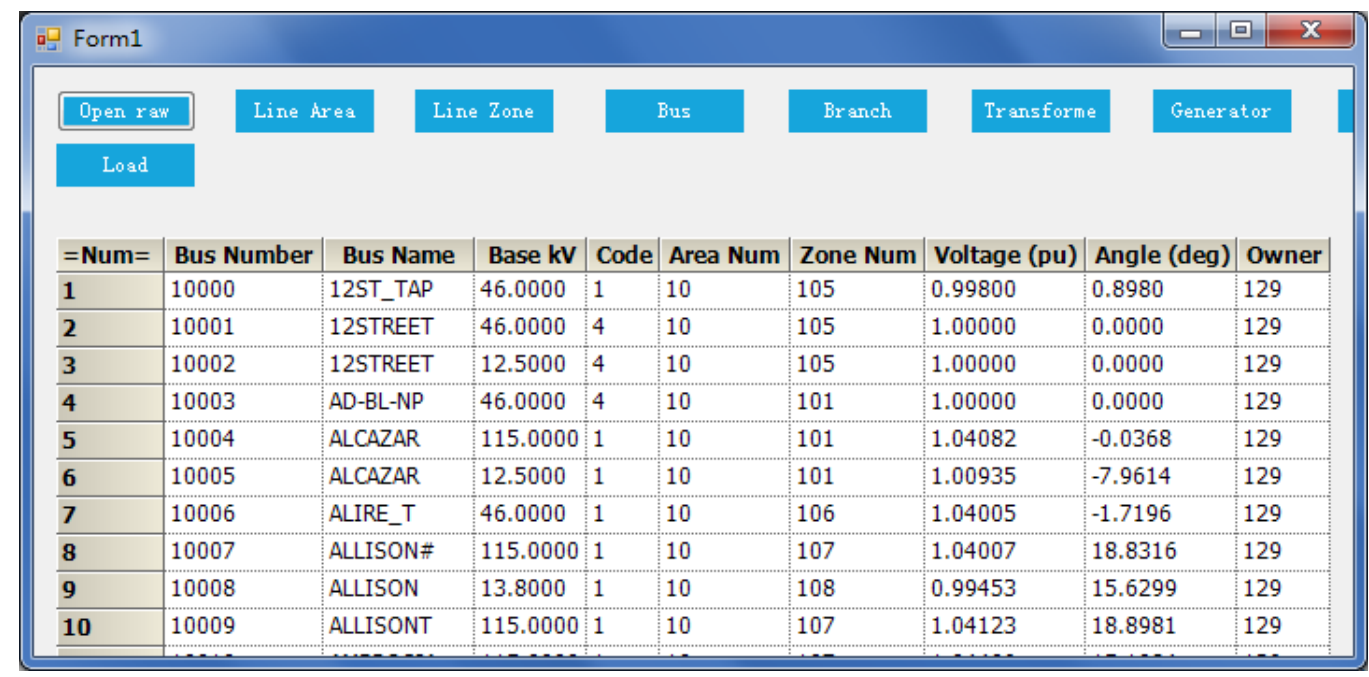

Fig. C.2. Bus information imported from PSS/E raw file.

\section{C.4 GRAPHICAL INTERFACE}

As illustrated in Fig. C.1, a power system model can be constructed and visualized by the C++-based interface. An overview of the interface is shown in Fig. C.3.

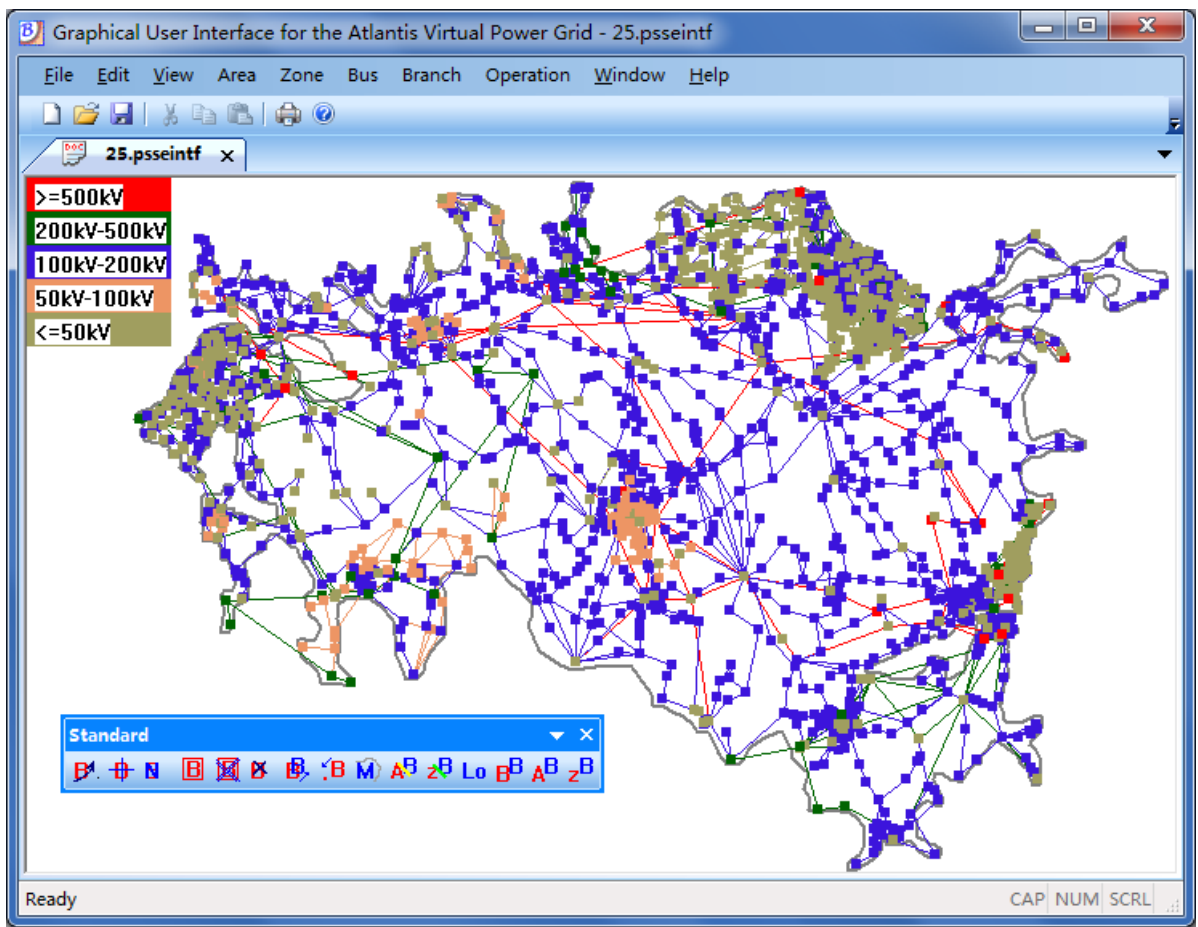

Fig. C.3. Main interface of GIPS.

The PSGT is organized by different menus which are shown below in Table C.1. Some of the function descriptions of various menus are also listed. Various display modes of the PSGT tool are shown in Fig. C.4. 
Table C.1. PSGT menus.

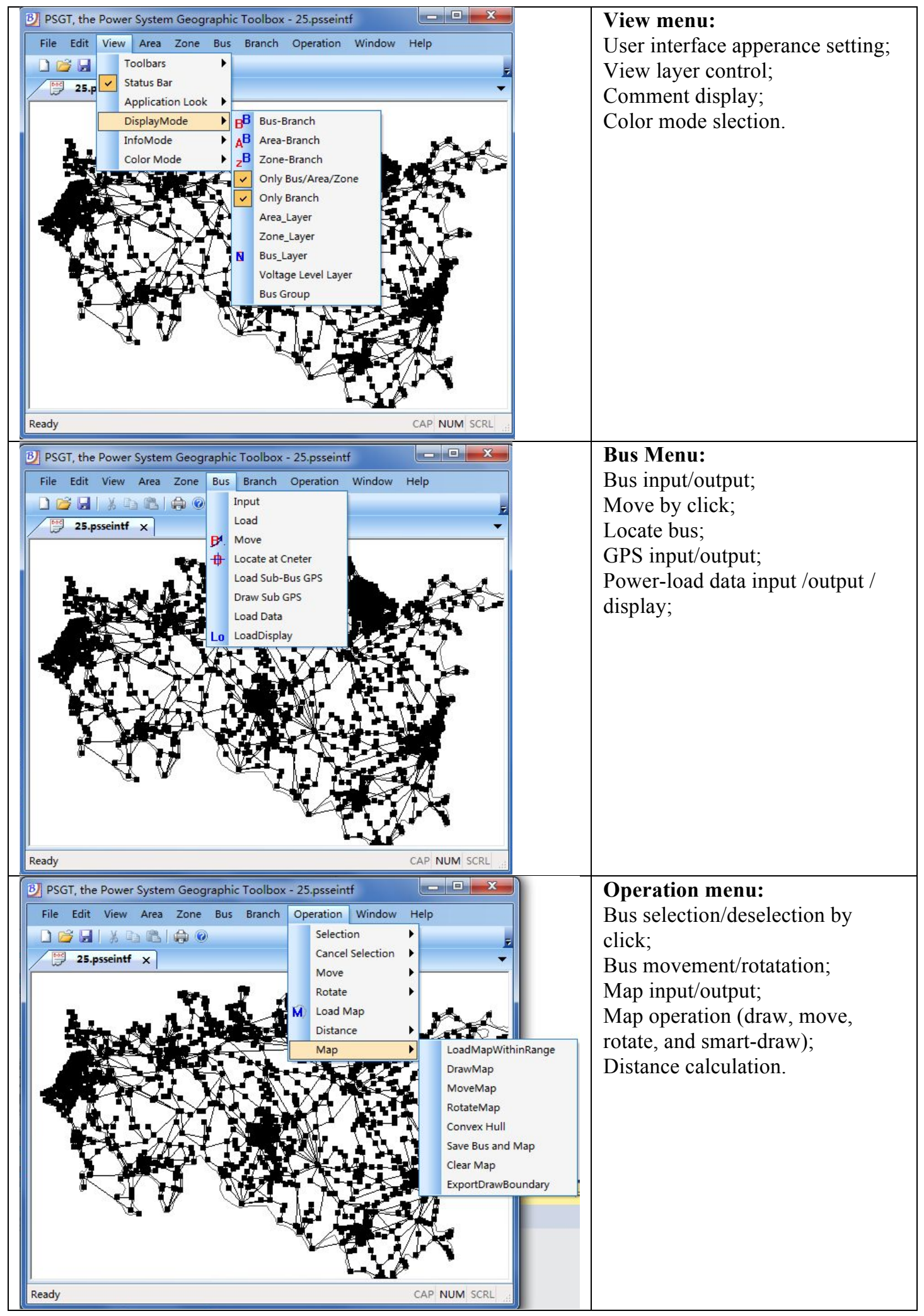




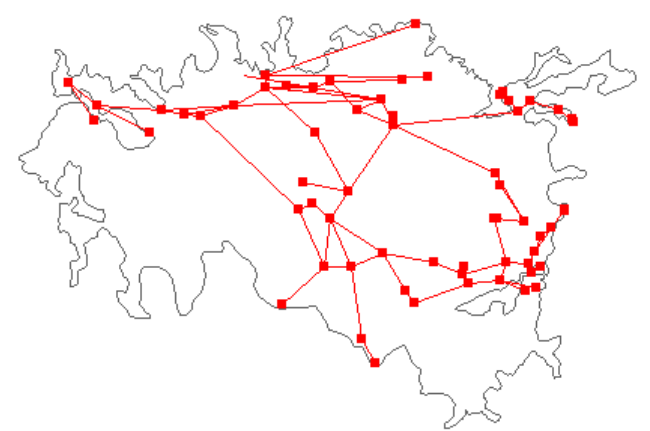

The 500-kV network
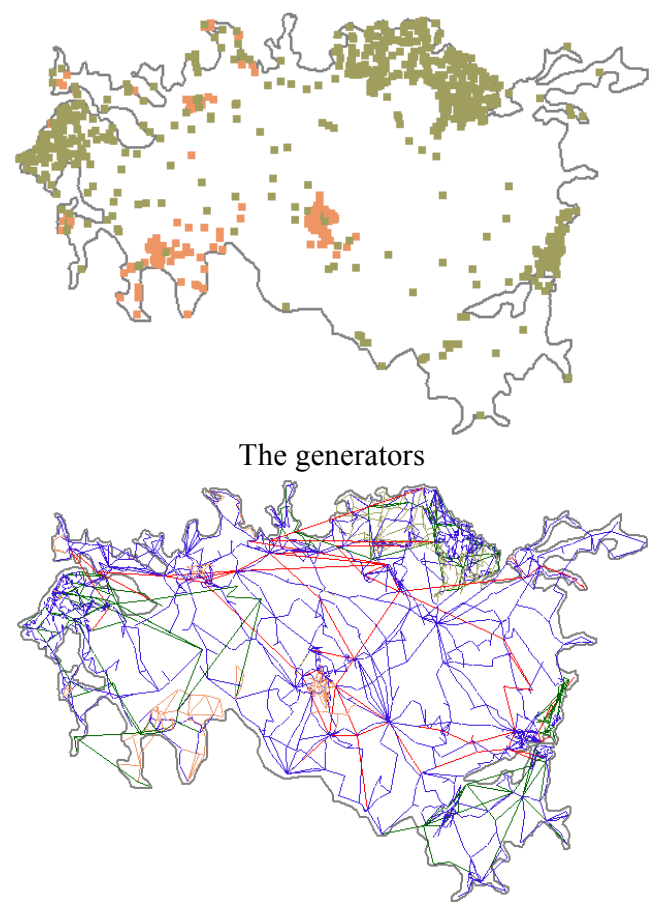

All the lines in color display mode

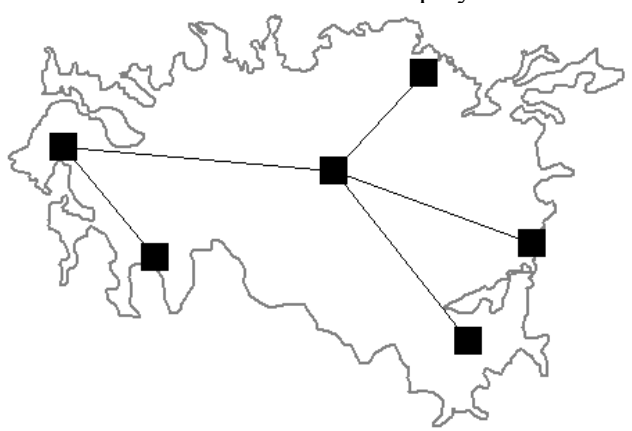

Area display mode

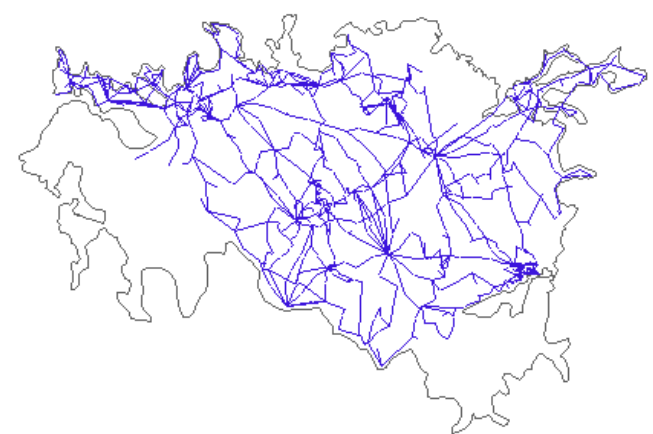

The 161-kV lines

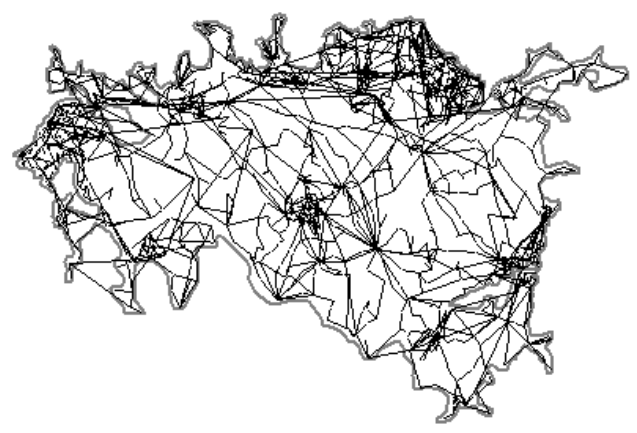

All the lines in black-white display mode

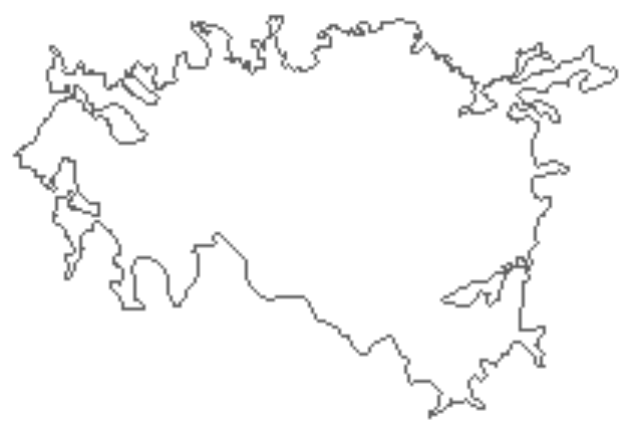

Boundary of the map

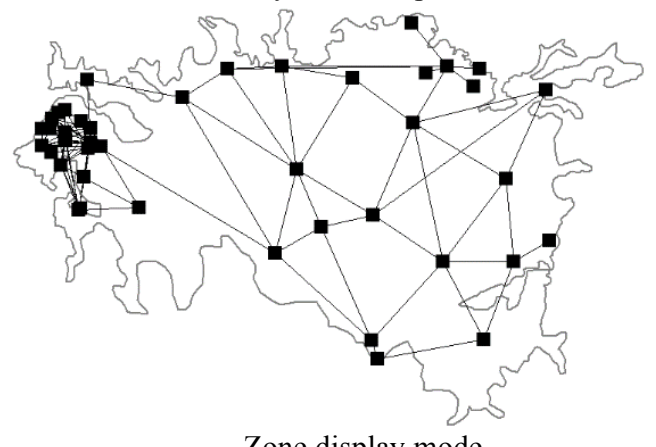

Zone display mode

Fig. C.4. Various display modes of this toolbox 


\section{C.5 GEOMETRIC ALGORITHM}

In this section, how the movement and rotation of certain parts of a power system is introduced. Within PSGT, movement is achieved by two clicks on the client region which are denoted by $\mathrm{P}_{1}$ and $\mathrm{P}_{2}$ in Fig. C.5.

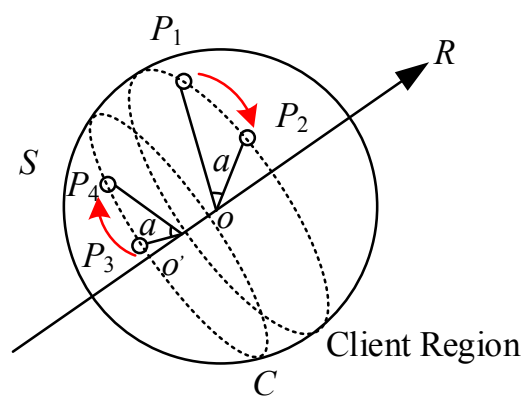

Fig. C.5. Bus movement on the spherical surface.

In Fig. C.5, the angle $a$ represents the counter clockwise angle between vector $\left(\mathrm{P}_{1}, \mathrm{o}\right)$ and $\left(\mathrm{P}_{2}, \mathrm{o}\right)$. The symbol 'o' stands for the center of the Earth. By the left-hand rule, the direction of the rotating axis $\boldsymbol{R}$ is $\left(\mathrm{P}_{1}, \mathrm{o}\right) \cdot\left(\mathrm{P}_{2}, \mathrm{o}\right)$. If one rotates $\mathrm{P}_{3}[x ; y ; z]$ by angle $a$ along axis $\boldsymbol{R}$, the coordinate of $\mathrm{P}_{4}\left[x^{\prime} ; y^{\prime} ; z^{\prime}\right]$ is

$$
\left[\begin{array}{c}
x^{\prime} \\
y^{\prime} \\
z^{\prime}
\end{array}\right]=\left[\begin{array}{ccc}
n_{x}^{2}(1-\cos \alpha)+\cos \alpha & n_{x} n_{y}(1-\cos \alpha)+n_{z} \sin \alpha & n_{x} n_{z}(1-\cos \alpha)-n_{y} \sin \alpha \\
n_{x} n_{y}(1-\cos \alpha)-n_{z} \sin \alpha & n_{y}^{2}(1-\cos \alpha)+\cos \alpha & n_{y} n_{z}(1-\cos \alpha)+n_{x} \sin \alpha \\
n_{x} n_{z}(1-\cos \alpha)+n_{y} \sin \theta & n_{y} n_{z}(1-\cos \alpha)-n_{x} \sin \alpha & n_{z}^{2}(1-\cos \alpha)+\cos \alpha
\end{array}\right]\left[\begin{array}{l}
x \\
y \\
z
\end{array}\right]
$$

where $\left[n_{x} ; n_{y} ; n_{z}\right]$ is normalized vector of $\left(\mathrm{P}_{1}, \mathrm{o}\right) \cdot\left(\mathrm{P}_{2}, \mathrm{o}\right)$.

Similarly, rotation is achieved by triple clicks on the client region which are denoted by $\mathrm{P}_{1}, \mathrm{P}_{2}$ and $\mathrm{P}_{3}$ in Fig. C.6.

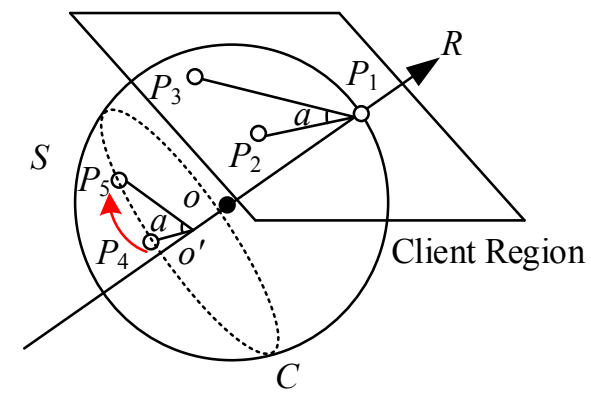

Fig. C.6. Bus rotation on the spherical surface.

The angle $a$ represents the counter clockwise angle between vector $\left(\mathrm{P}_{1}, \mathrm{P}_{2}\right)$ and $\left(\mathrm{P}_{1}, \mathrm{P}_{3}\right)$, with ' $\mathrm{o}$ '" being the project point of $\mathrm{P}_{4}$ on rotating axis $\boldsymbol{R}$. The rotating axis $\boldsymbol{R}$ points from the spherical center 'o' to $\mathrm{P}_{1}$. If one rotates $\mathrm{P}_{4}[x ; y ; z]$ by angle $a$ along axis $\boldsymbol{R}$, the coordinate of $\mathrm{P}_{5}\left[x\right.$ '; $y^{\prime} ; z$ '] is 


$$
\left[\begin{array}{l}
x^{\prime} \\
y^{\prime} \\
z^{\prime}
\end{array}\right]=\left[\begin{array}{ccc}
n_{x}^{2}(1-\cos \alpha)+\cos \alpha & n_{x} n_{y}(1-\cos \alpha)+n_{z} \sin \alpha & n_{x} n_{z}(1-\cos \alpha)-n_{y} \sin \alpha \\
n_{x} n_{y}(1-\cos \alpha)-n_{z} \sin \alpha & n_{y}^{2}(1-\cos \alpha)+\cos \alpha & n_{y} n_{z}(1-\cos \alpha)+n_{x} \sin \alpha \\
n_{x} n_{z}(1-\cos \alpha)+n_{y} \sin \theta & n_{y} n_{z}(1-\cos \alpha)-n_{x} \sin \alpha & n_{z}^{2}(1-\cos \alpha)+\cos \alpha
\end{array}\right]\left[\begin{array}{l}
x \\
y \\
z
\end{array}\right]
$$

where $\left[n_{x} ; n_{y} ; n_{z}\right]$ is normalized vector of $\boldsymbol{R}$. 
